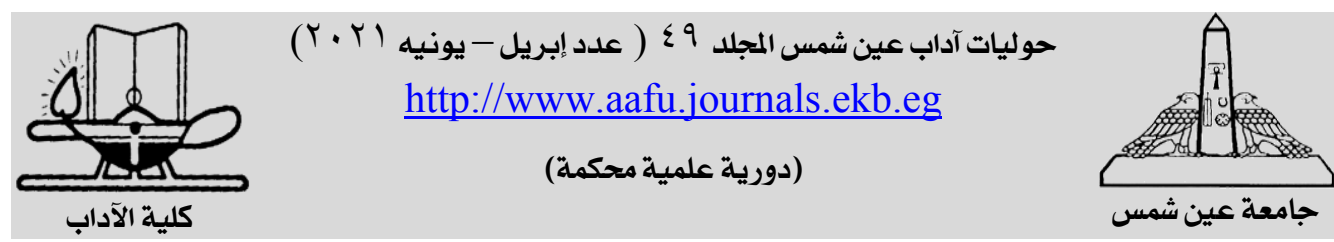

\title{
آلية اشتغال التفكيك بالهدم والبناء في المسرح العراقي
}

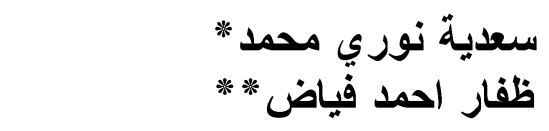

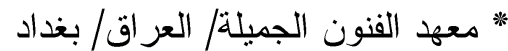

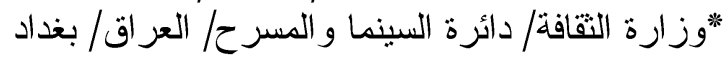

Saadia.noori222@gmail.com

إن للتفكيكية دور ا مركزيا في عروض ما بعد الحداثة المسرحية، و التقكيكية هي التئي

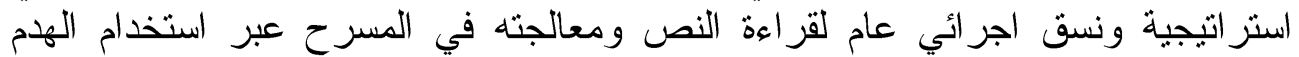

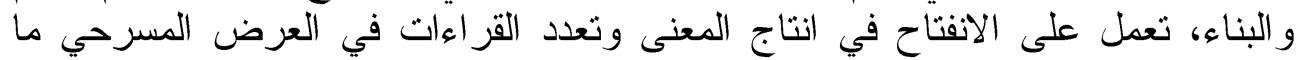

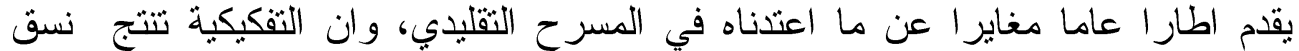

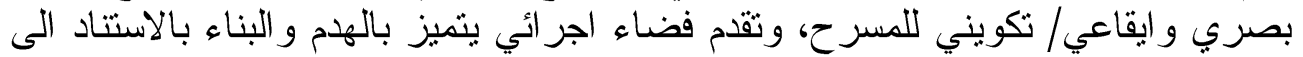
المقو لأت الجوهرية للتفكيكية. وقد قسم الباحثان هذا البحث الى الإطار المنهجي وفيه اهمية البحث وهدف

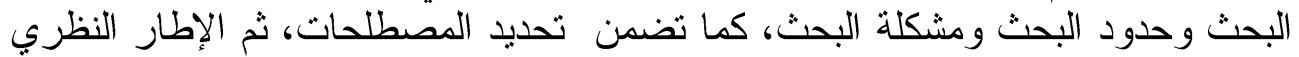

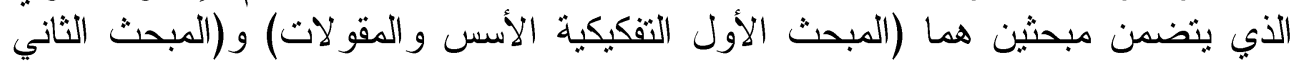

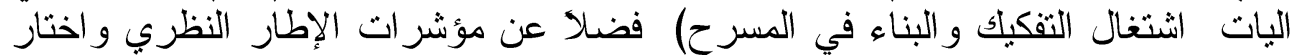

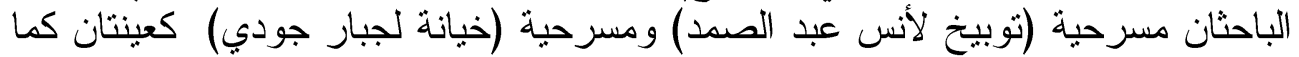

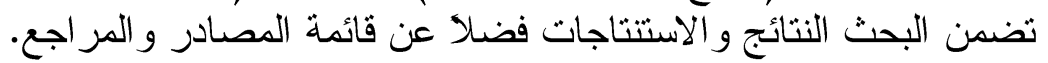

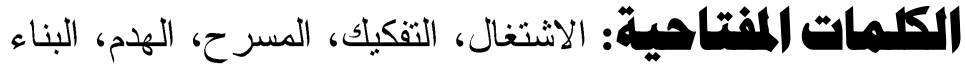




\section{الفصل الأول}

مشكبة البحث

ان التقكيكية تتتج نسق بصري و ايقاعي/ تكويني للمسرح، و تقام فضاء اجر ائي

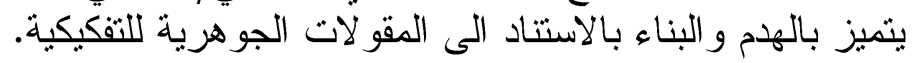
وقد حددت مشكلة البحث بالسؤ ال الآتي: - كيف يجزي لاتئ عمل التفكيك بالهدم و البناء

تتجلى اهمية البحث في ثقديم دراسة معرفية من اجل فهم و ادر الك الية اشتغال التقكيك بالهدم و البناء في المسرح البح العر اقي. يفيد الباحثين في هذا المجال من مخرجين المين مسرحيين ومؤلفين او ممن يمارسون الاعداد للمسرحيات، او من العاملين في وضع تصميم السينو غر افينا.

هدف البحث الكثف عن الكيفية التي يستخدم فيها التفكيك بالهدم و البناء في العروض المسرحية. حدود البحث يتحدد البحث فيما بأتي:

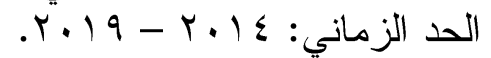
الحد المكاني: بغداد - ( المسرح الوطني ـ الوطي ومسرح ح الر افدين ومنتدى المسرح ) ).

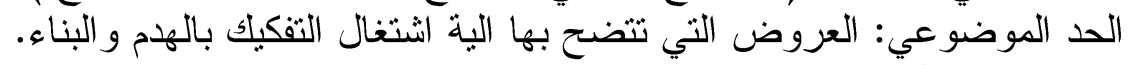

عرفت في الأصل اليوناني على انها الألية بمعنى (الحيلة، الأداء، الآلة، الوسيلة)

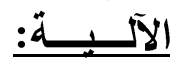

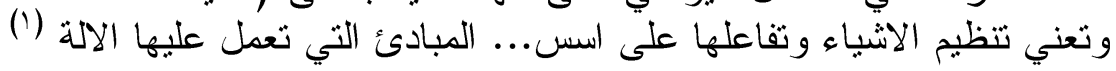

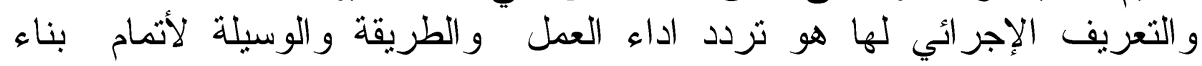
العرض بعد التقكيك.

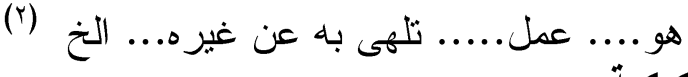
الاشثتغال التفكيكية

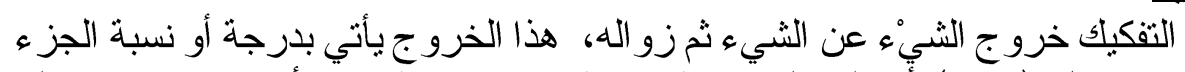

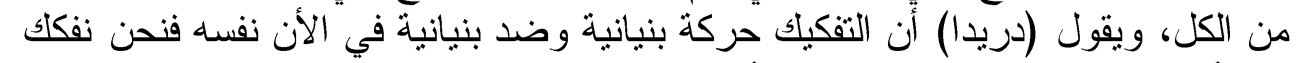

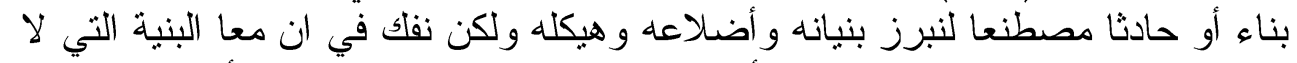

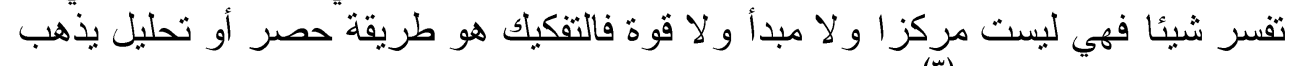

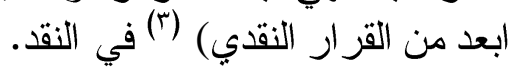

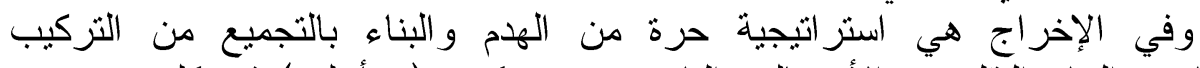

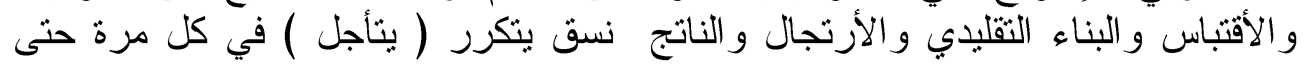

هو نظام من الأجزاء المتز اكبة و المجمعة من اجز اء صغيرة معقدة لتصنع نظام العرض الكلي، وقد عرفه ليون ليفينش على الهن " نسق قائم على الوحدة الداخلية للكل 


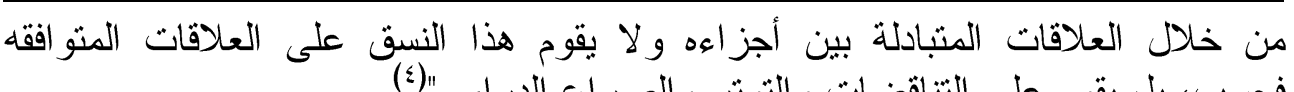

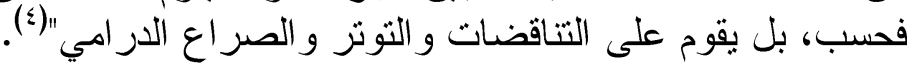

هو حط البناء و اسقاطه، وهدمت الحائط أهدمه، اسقطه من اقامته (0).

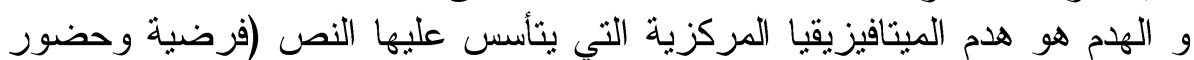

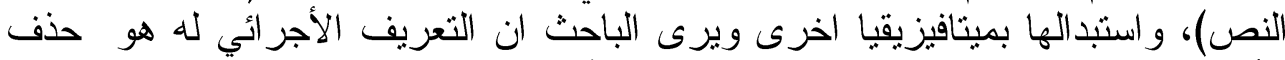

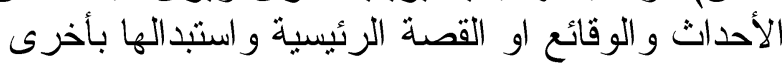

\section{الفصل الثاني}

المبحث الأول: التفكيكبة الأسس والمقولات التهية

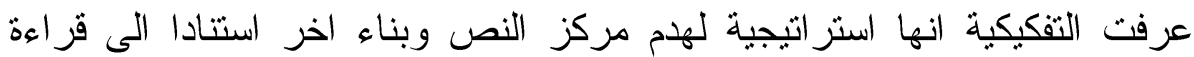

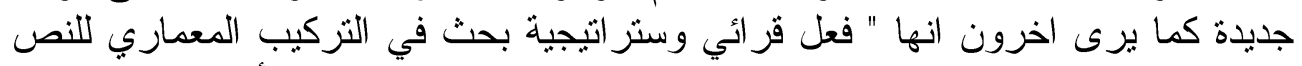

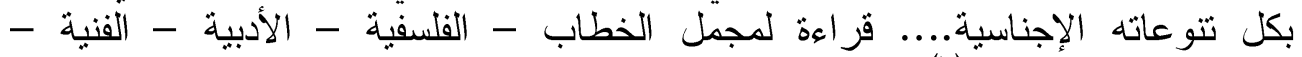

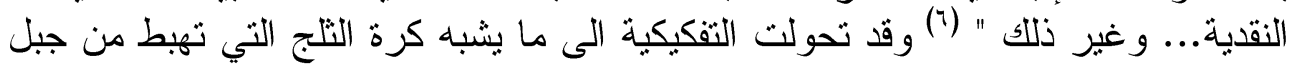

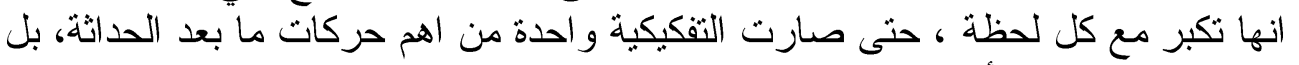

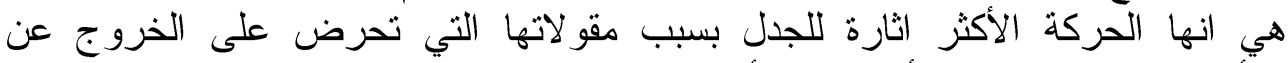

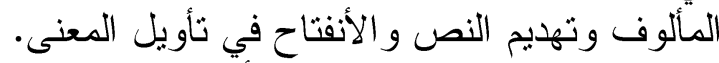

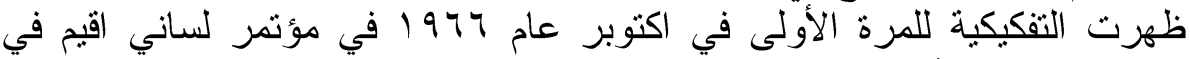

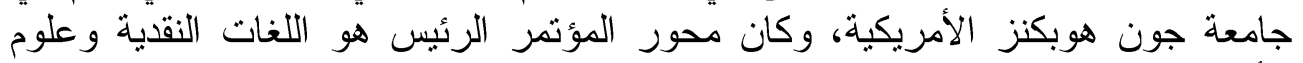

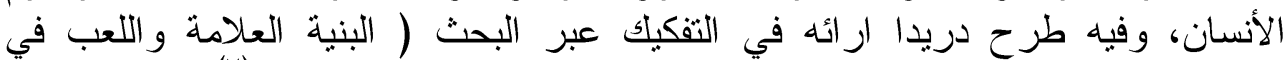

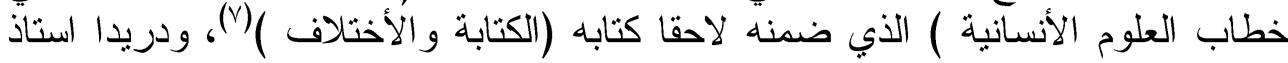

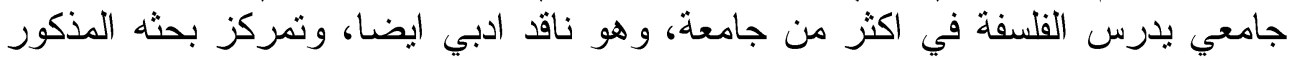

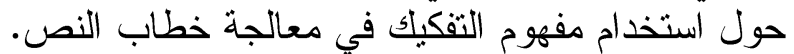
ويتضح بعد العودة الى الأصل الفرنسي للمصطلح ( ) deconstraction )، وهي الفي

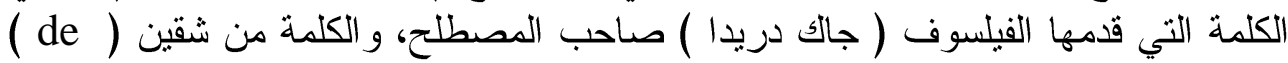

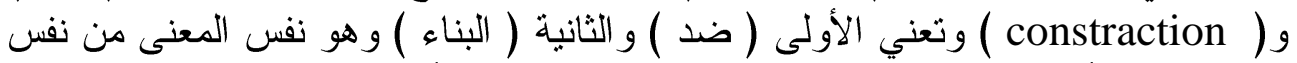

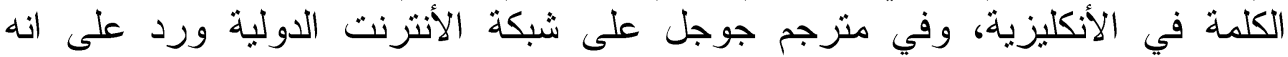

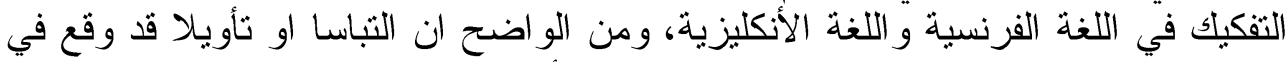

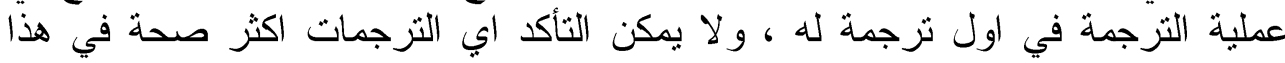

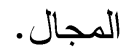

و القول التفكيك و الهدم و البناء بشير الى منو البة عمل على نص وتعريضه نائه

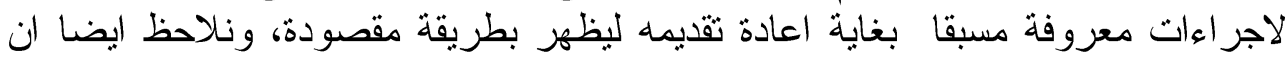

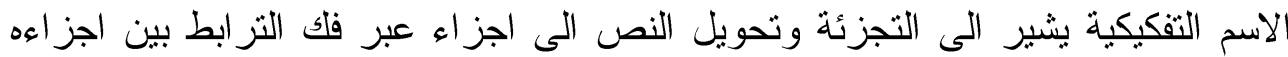

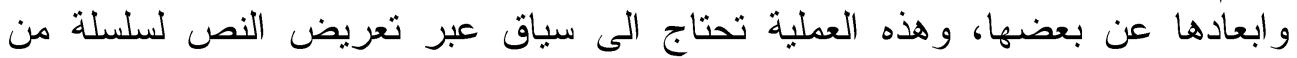

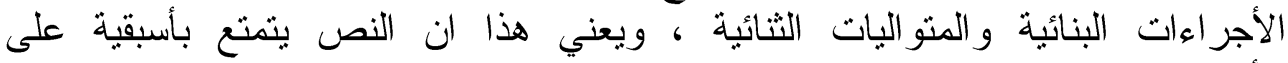

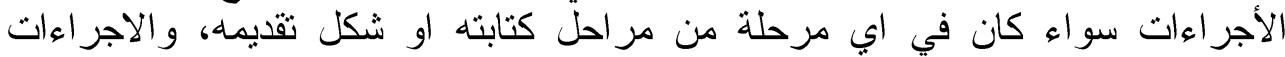

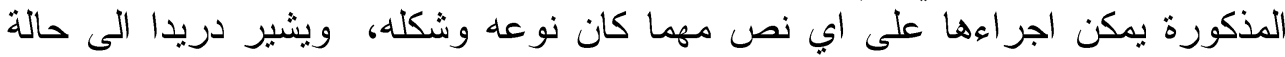
الهام التي يفقد بعدها النص " كل مصدر يعود اليه فتتلاشى مشكلة الحقيقة والمعرفة

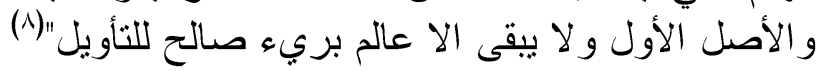


جاءت التفكيكية ردا على البنيوية اللغوية وهي نظام متقابل من الأشارات نات نادى بهابه

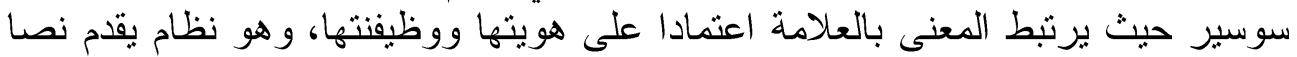

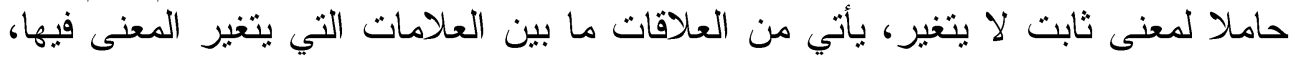

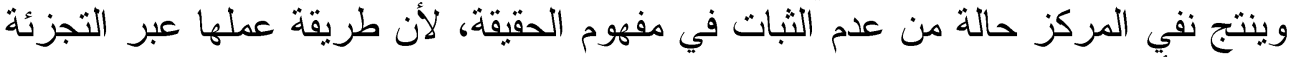

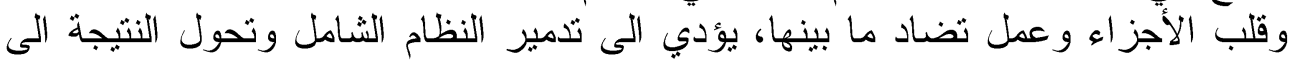
شكل ثوري يتكرر ويصبح التأويل عدد منو الي من الهروب من الأل الحقيقة مع صعوبة في

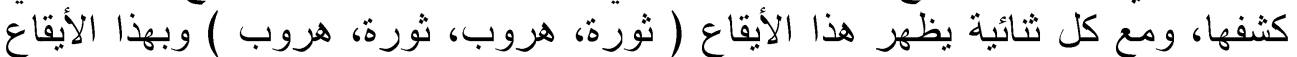

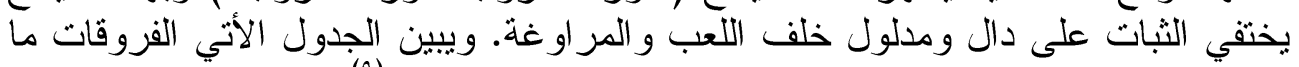

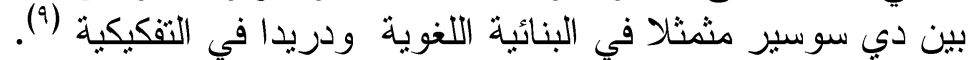

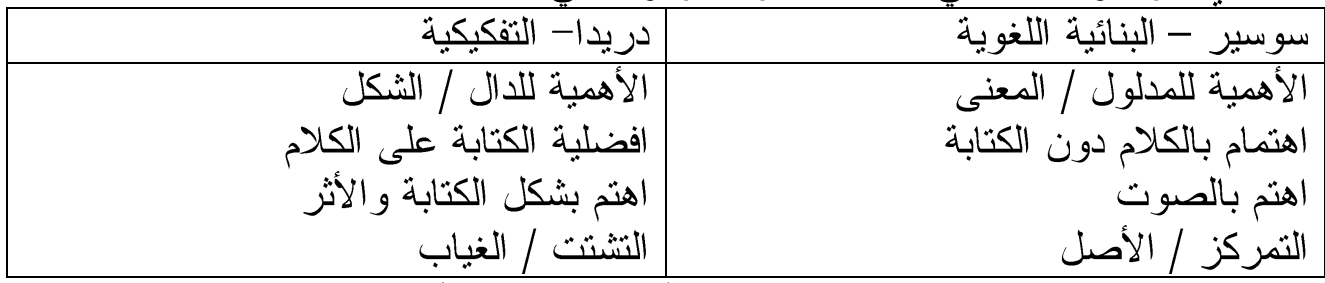

وقد استتدت التفكيكية الى ثنائية ( الثك و اليقين ) و الجدل الثياب حول ايجاد مركز

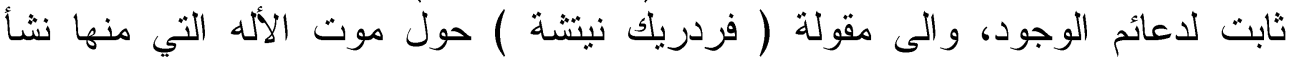

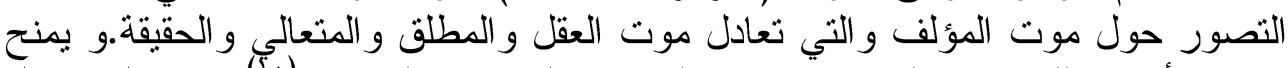

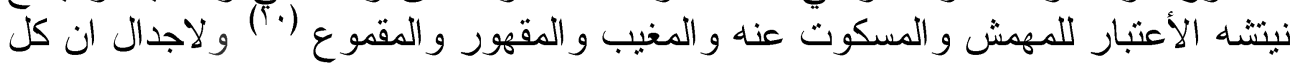

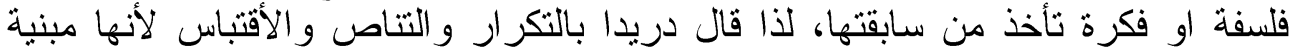

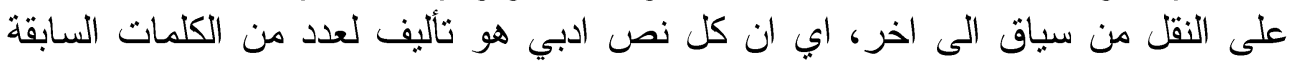

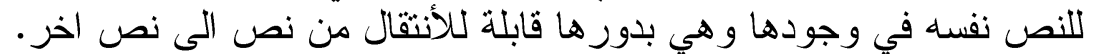

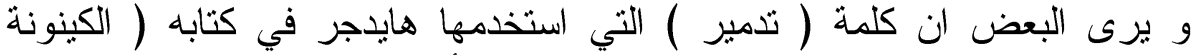

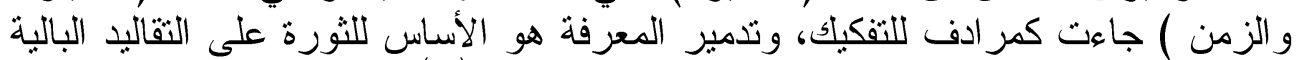

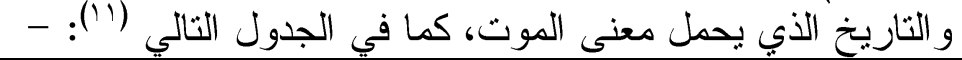

\begin{tabular}{|c|c|}
\hline جاك دريدا & مارتن هيذجر \\
\hline الأرجاء / الأختلاف & Doesein او الدازين \\
\hline التقكيك & التدمير \\
\hline الظاهر & الحاضر \\
\hline المباشر & الو اقع \\
\hline
\end{tabular}

و اعتبر ميشيل فوكو الخطاب نشاط انساني مركزي، ويتحدث هنا عن خطابات التهات

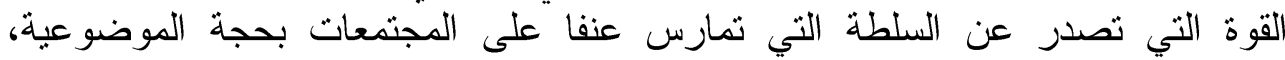

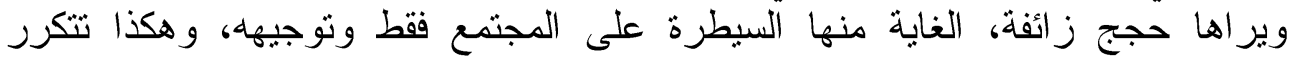

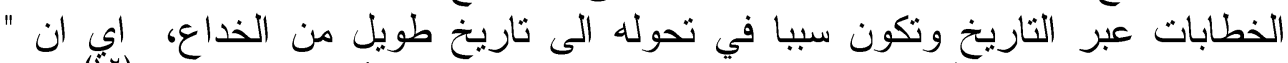

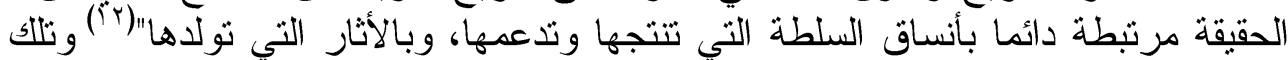

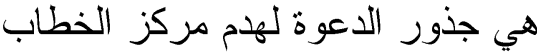

و يتفق اغلب الباحثين ان المرتكزات الأساسية للتفكيكية هي: -

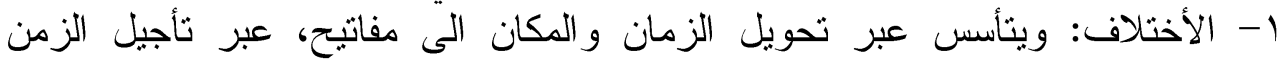

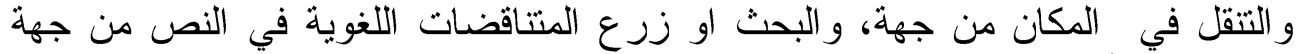

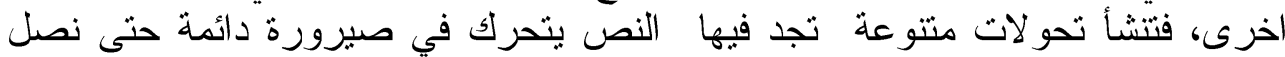

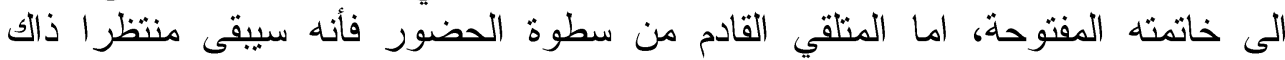


الحضور البديل الذي يقدمه النص دون ان يجده، وفي فورة البحث عن المعنى و انتظاره

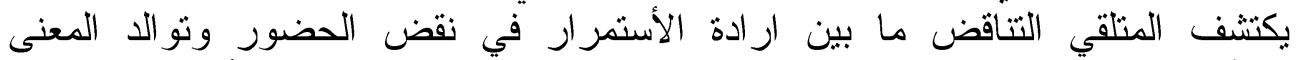

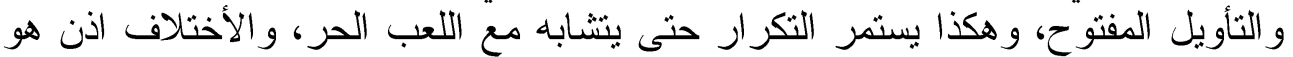

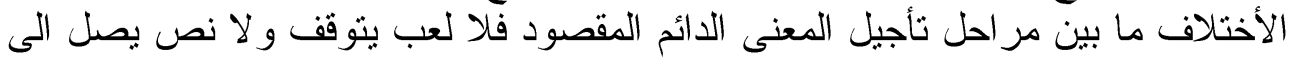

معنى او نتيجة و اضحة في النهاية، فيضيع الحضور تاركا خلفه اثار ثم اثار فقط

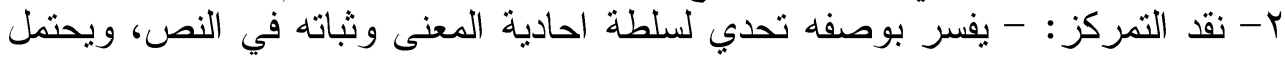

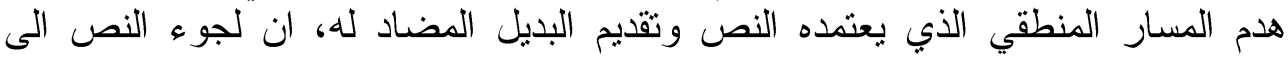
ميتافيزيقيا العقل، يعني التمركز حول مصدر عقلي ثابت مرجعيته تستند الى مركز خاري

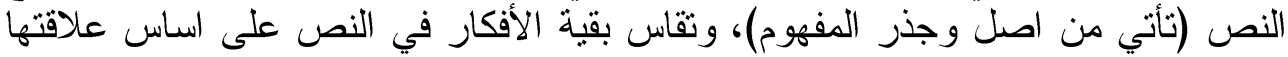

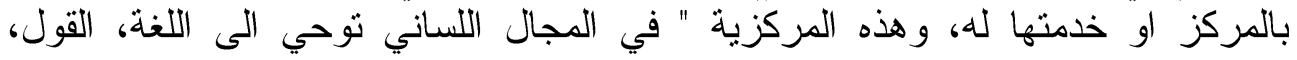

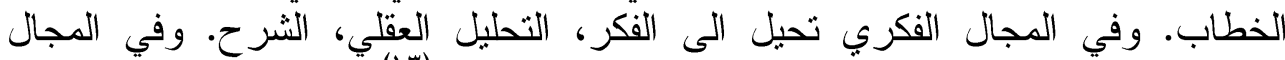

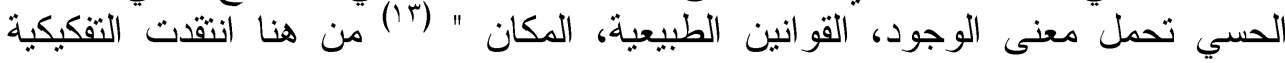

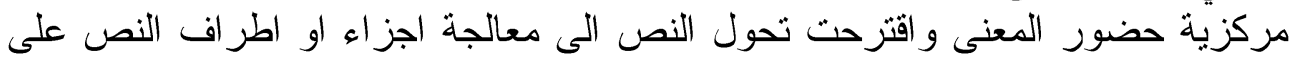
اساس الثنائيات في النص او نقاط الفرى الفر ير اها القارئ.

و يرى دريدا ان الفكر الغربي هو فكر عقلي يتمركز غالبا حول الفيا سلطة خارجية

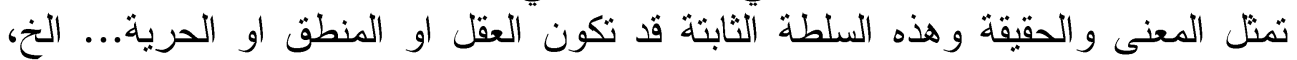

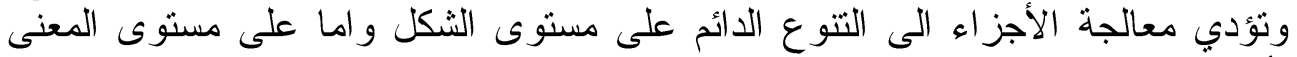
فأن التقكيكية التي تتادي بتدمير وتقديم الهو امش تصل التي التى ما يدعى بغياب معنى رئيسي

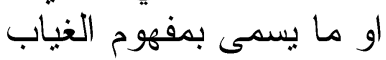
r- اللعب:- يقترن اللعب بالحرية و التتوع و التجدد، ان التأجيل الدائم وتجزئة النص

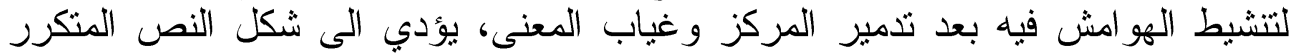

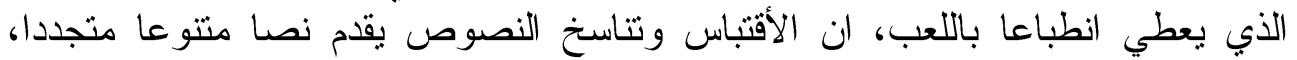

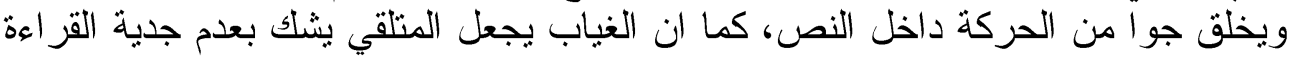
ما يعطي انطباعا باللعب و الكاريكاتيرية دانية ع- الكتابة:- ان التمركز المنطقي هو تمركز صوتي لألئي يعود اللى ما فبل استخدام الكتابة،

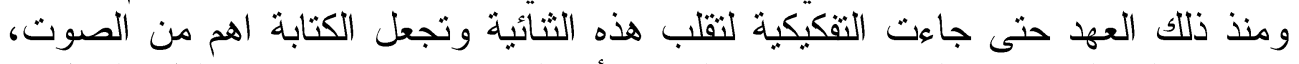
اي ان "التفكيك اعتمد الكتابة بدلا من الكلام لأن الكلام.. يعني احتكار سلطة الخطاب،

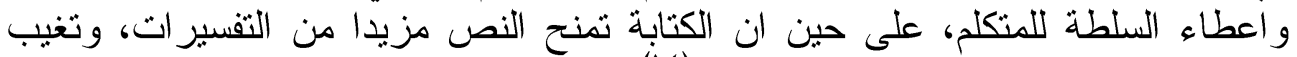

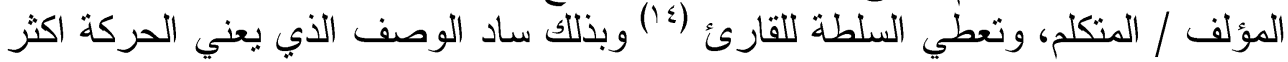

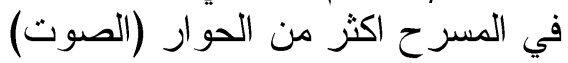

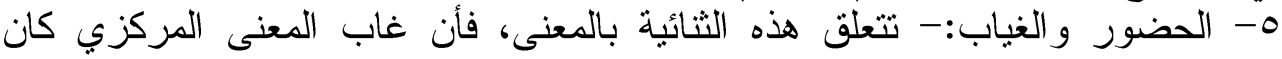

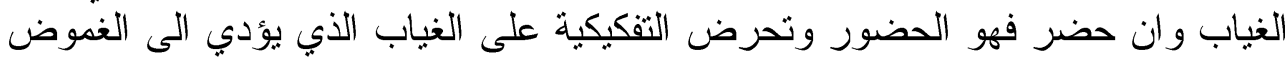

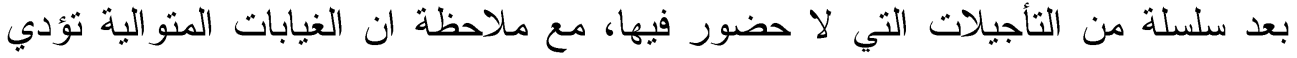

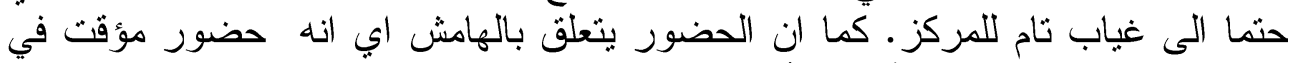

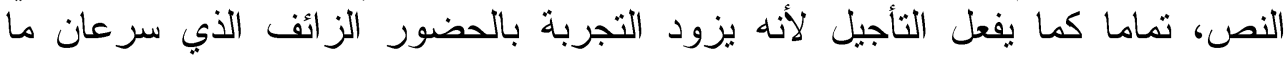

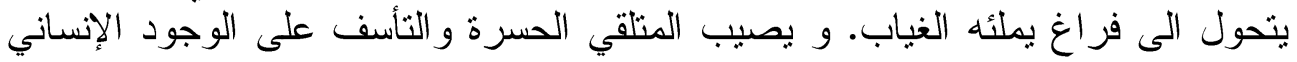
بعد انتظاره الطويل للحضور دون اغي رد من النص بسبب معنى الغموض و الغياب. 
تبحث التفكيكية عن البنية القلقة والغير مستقرة داخل النص، وينطلب الأمر قر اءة

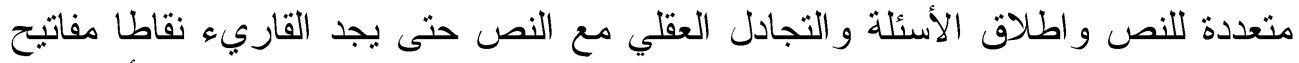

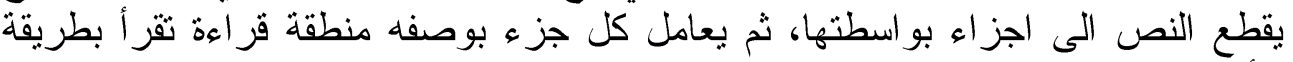

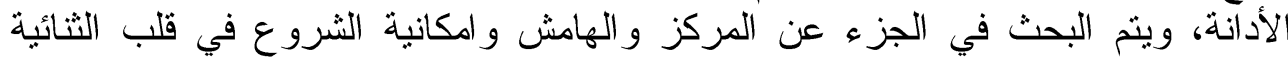

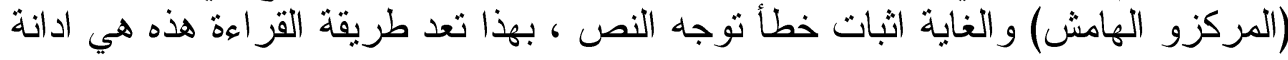

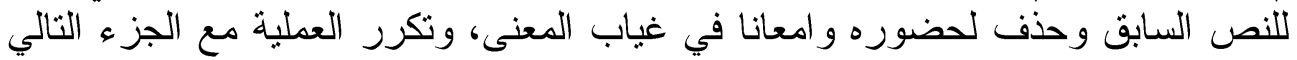

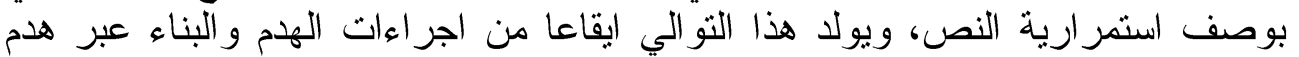

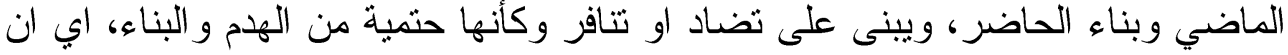

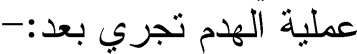

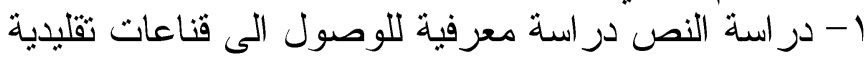
r- استخر اج الثنائيات من النص او اضافة بعضها ان لم توجد التهات وتحديد الجانب المركزي

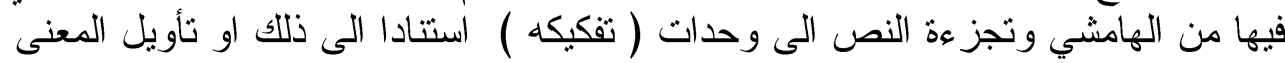

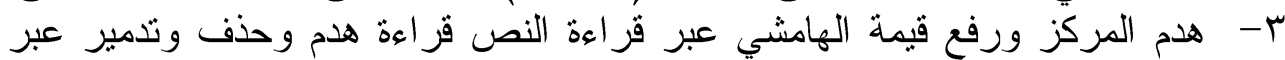
حذف وقلب اطر اف الثنائبات ع- الأفتاح في الكتابة وتقليل الأعتماد على الكلام، و التحول الى الوصف بدلا من السرد

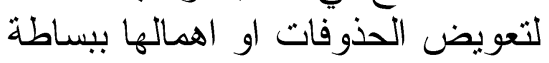

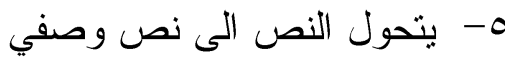

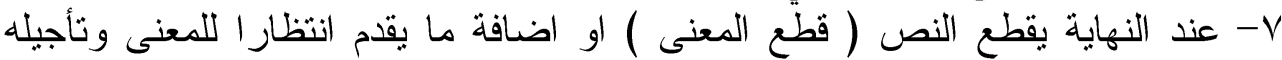
وتقديم نظام النهاية المفتوحة كأثر من الماضي المع تأجيله الى المستقبل

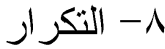

و على هذا فأن النتيجة المنطقية للنص هي مجموعة من المقاطع و الأجزاء خالية

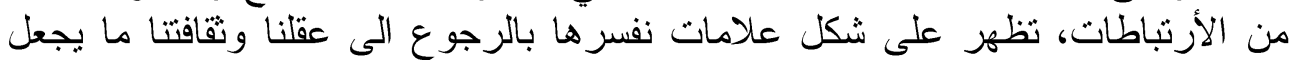

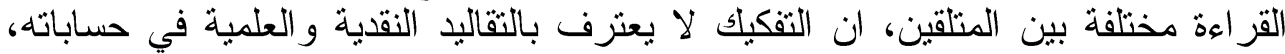

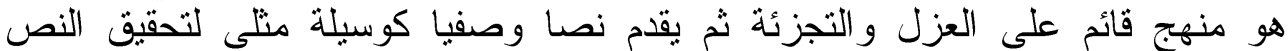

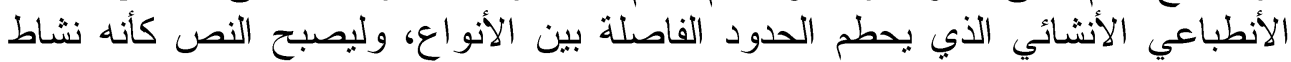
تعبيري وصفي رومانسي.

\section{المبحث الثاني: البات الثتنغال التفكيك بالّهنم والبناء في المسرح}

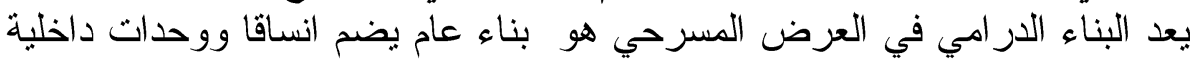

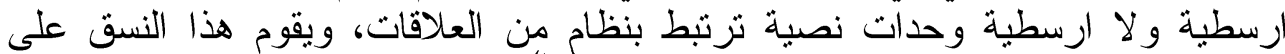

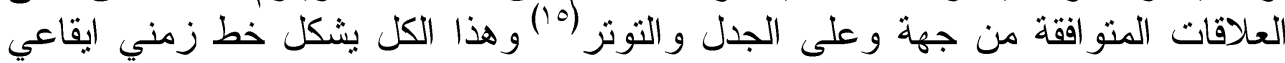

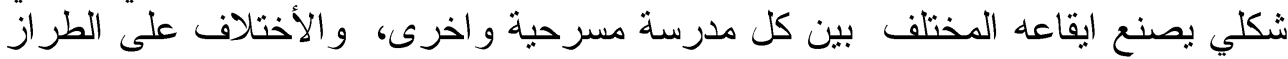

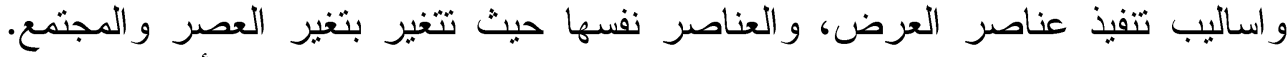

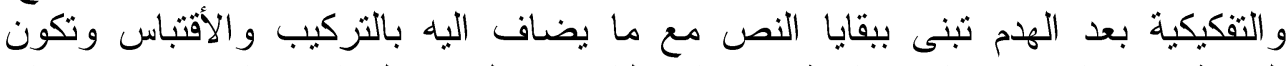

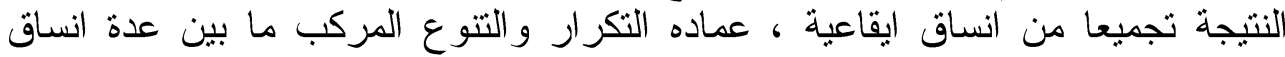

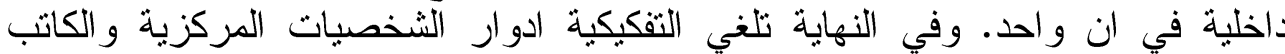

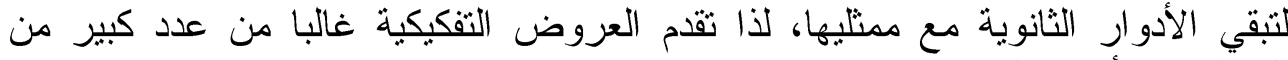
الممثلين و الأدو ار الصغيرة.

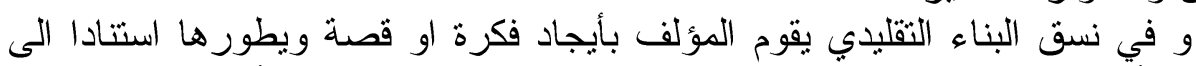
تصاعد الأحداث وصولا الى الُعقدة او (الحبكة) يليها النزول وفلك الأشتباك و الحل في الئي 
النهاية ويعد هذا نسقا شكلبا تقلبديا قام بالصمود منذ الأغريق حتى الرومانسية او ما قبل

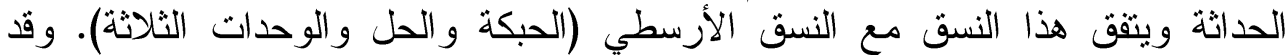

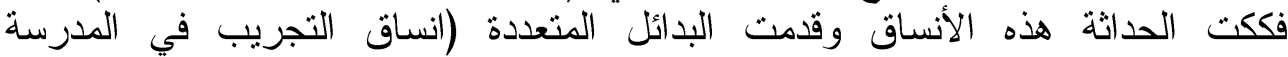

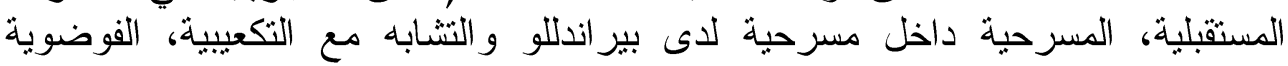

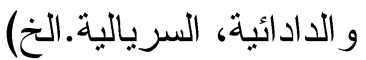

ومع قدوم ما بعد الحداثة في الستينات ولدث التهات التفكيكية وحولت النص التى ساحة

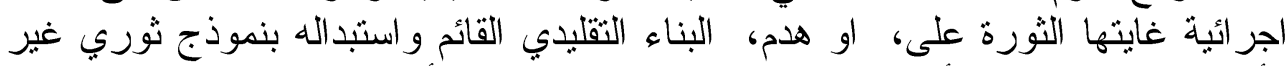

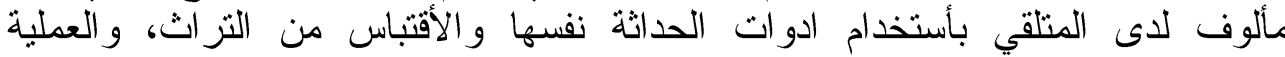

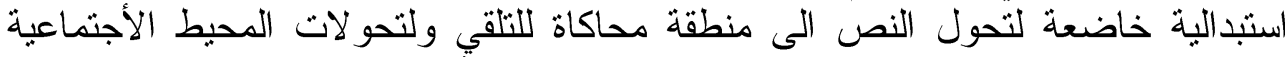

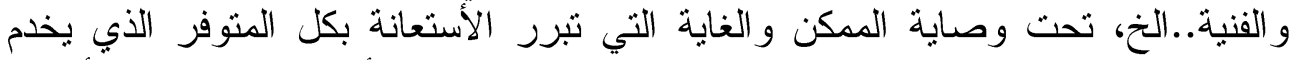

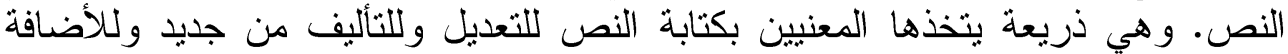
و الحذف السريع لتحقيق النص بأقصر مدة ممكنة تماشيا مع المعطبات التي تعيق اون تشهل

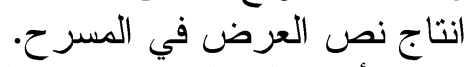
أن ثو الي الي من تعدد المشاهد و المفاهيم التي ثرمم بالأرتجال و الأفكار المتتاصة

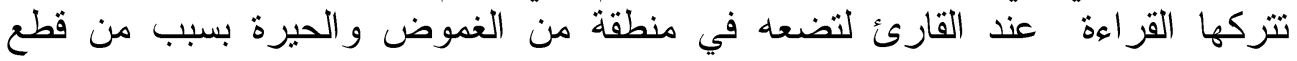

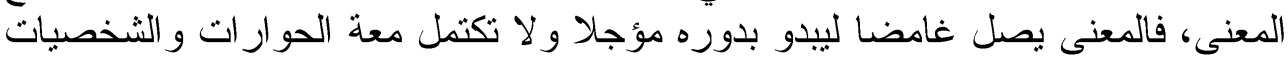

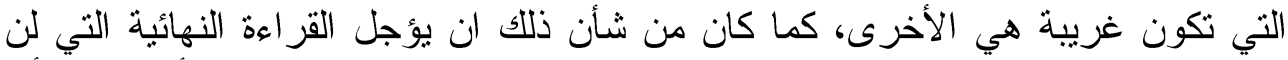

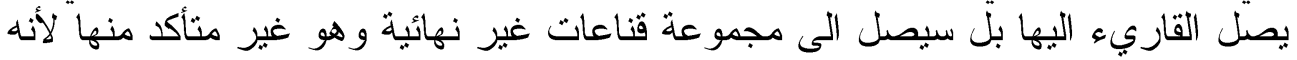

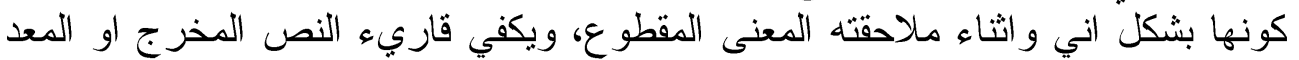

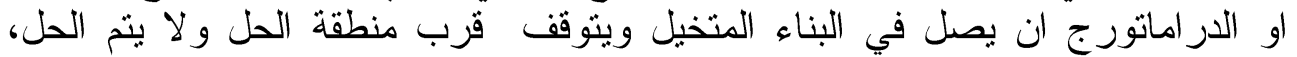

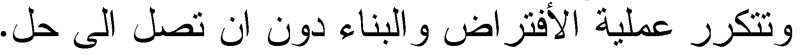

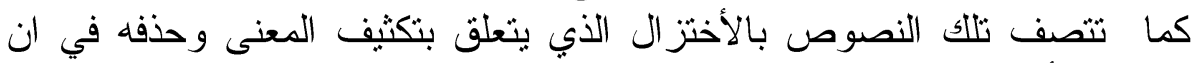

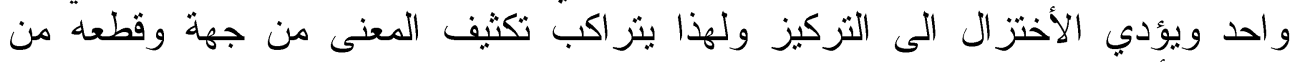

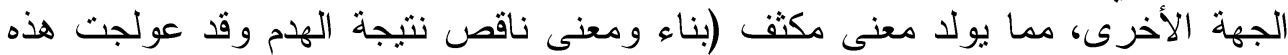

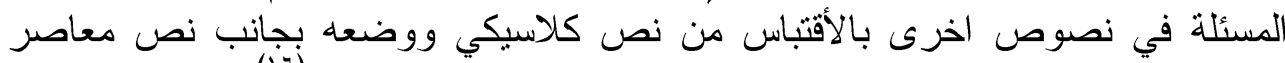

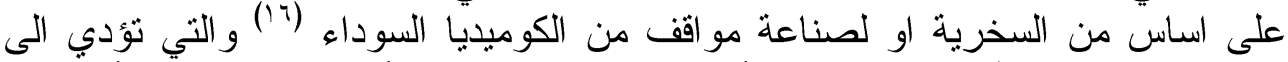

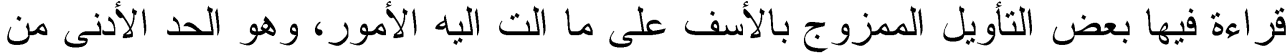

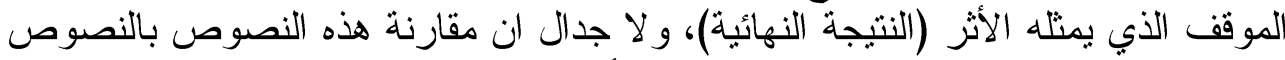

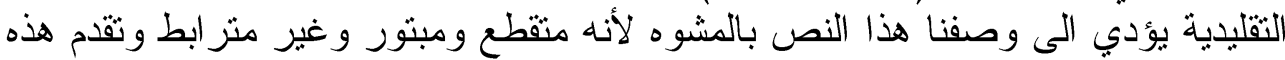
البنية غير الو اضحة احساسا بعدم الأسنقرار.

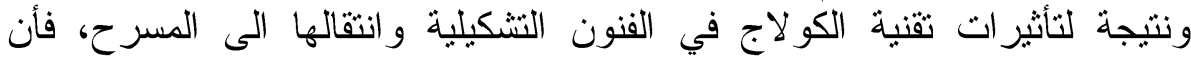

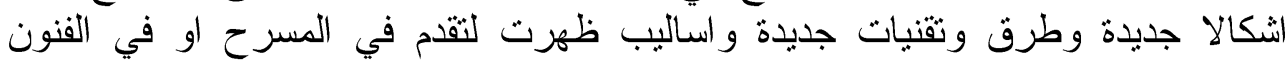

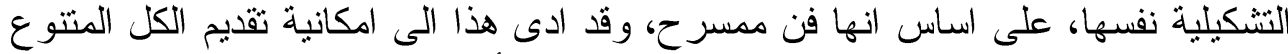

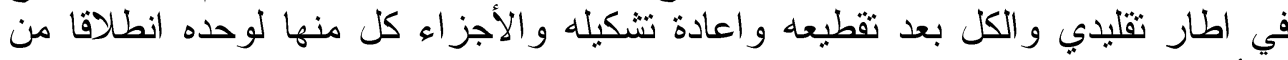

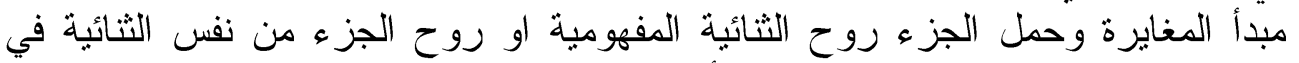

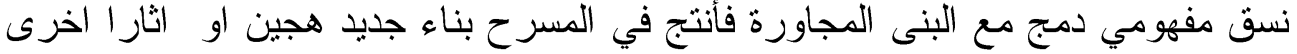


1- مسرحيات تتطلق من ورقة عمل وتمارين الخبال التي تثطور الى قصص التص صامتة

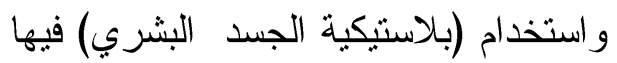
r- مسرحية يتم حذف الز ائد من حوارها وتجميع الباقي الغير مثز ابط ويكون الباقي هو نص العرض الذي يقدم بطريقة تقلبدية ب- مسرحيات معروفة احداثها يعاد ثألبف مركز ها و استبداله بهامش او حدث من نفس

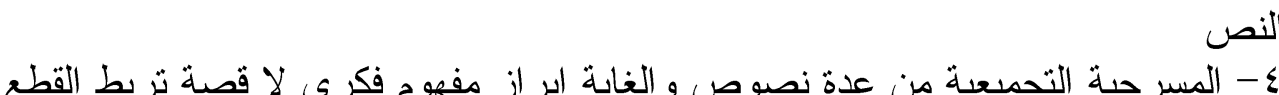

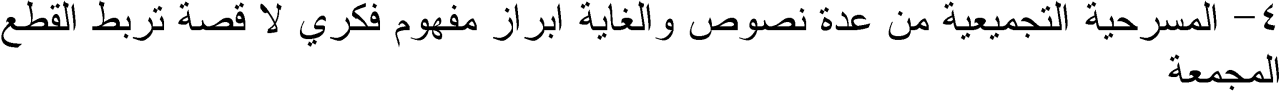
ه- مسرحبات تجميعية تشكيلية صامثة لا تبنى على اساس در امي بل تجمع لبع على اساس

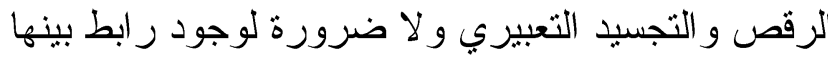

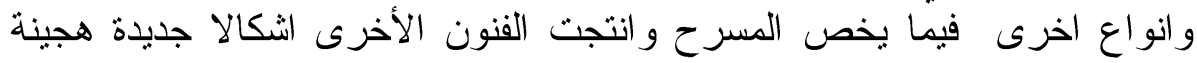
ايضا مثل ما انتجته الفنون النشكيلية مثل: -

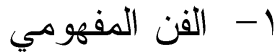

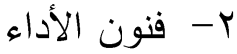

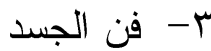
ع- الحدوثية ( الهابنتج ).. الخ الخ الخ

كما فسح هذا التفكيك المجال امام استخدام تقنيات من البنى المجاورة في توظيفها

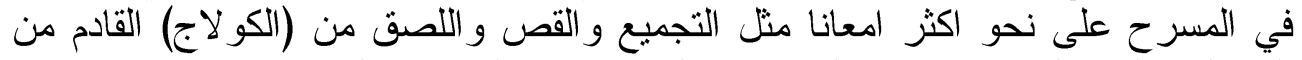

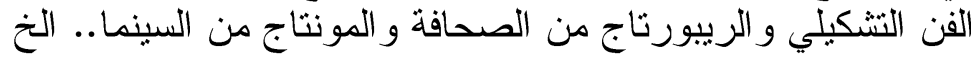

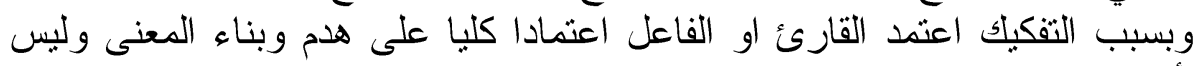

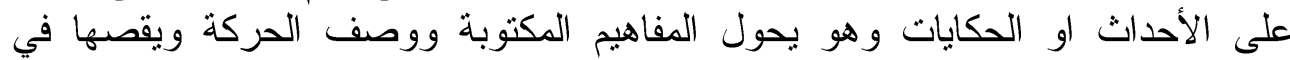

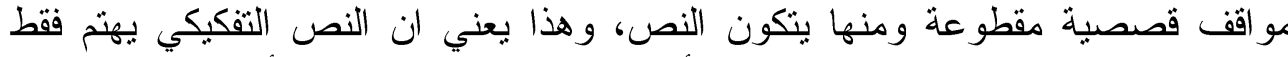

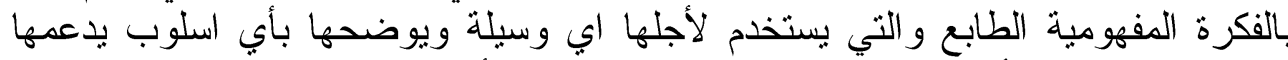

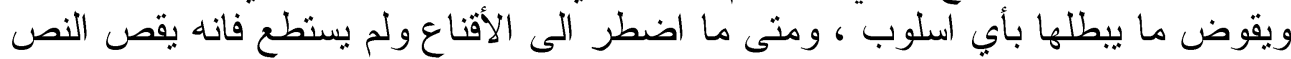

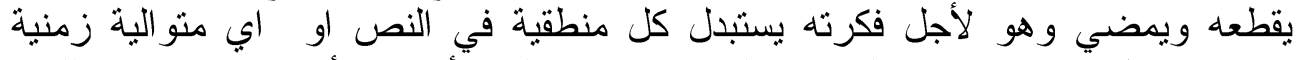

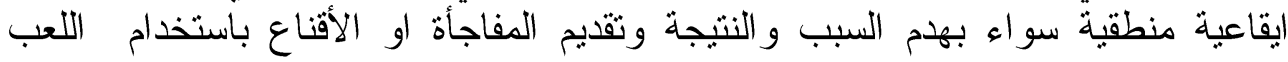

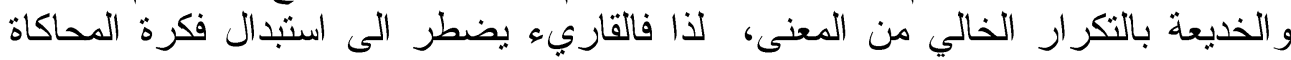

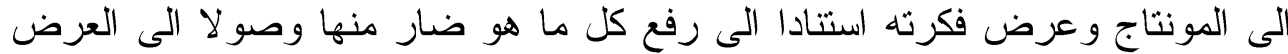

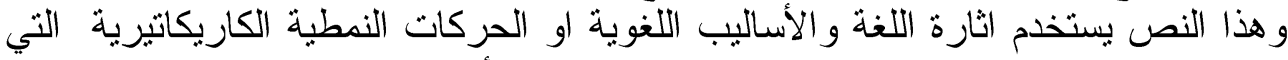

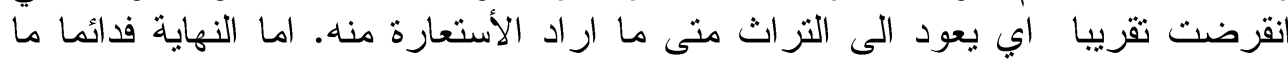

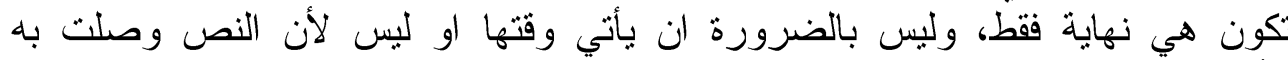

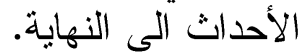

الإعرض

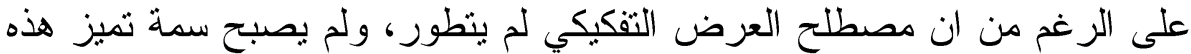

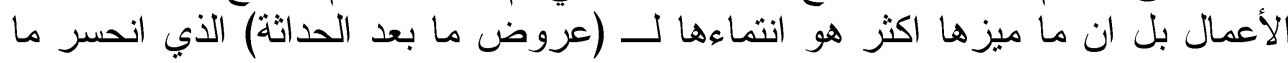

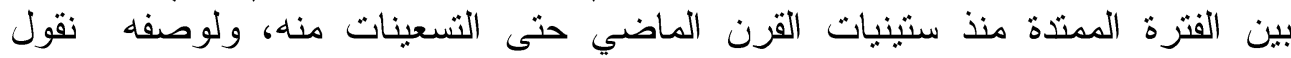

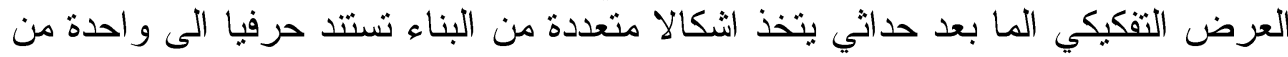

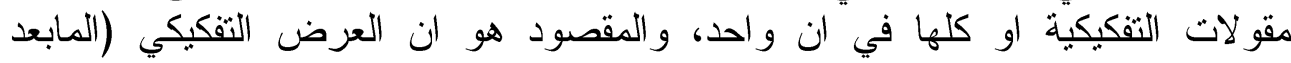

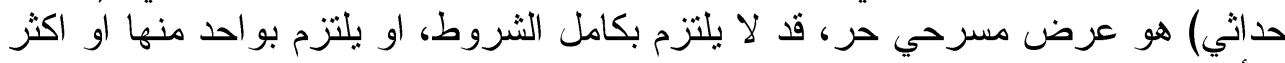
فالأمر مرتبط بطبيعة القراءة وبنائيتها ومكوناتها، ما دام جميعها يتقق على عدم تمام 


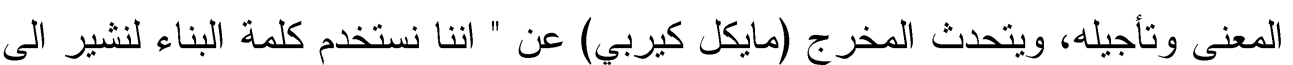

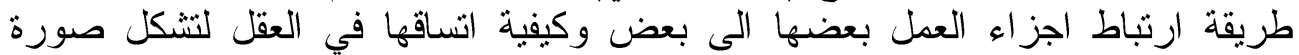

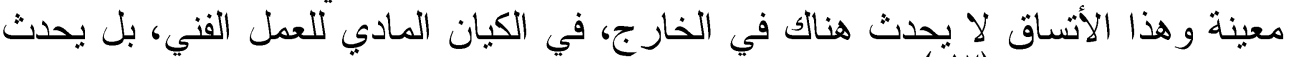

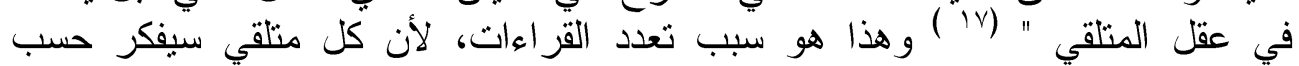
مرجعيته بطريقة مختلفة، كما ان هدم مرجعية المركز ، مثل بناء نص مختلف عن الأصل

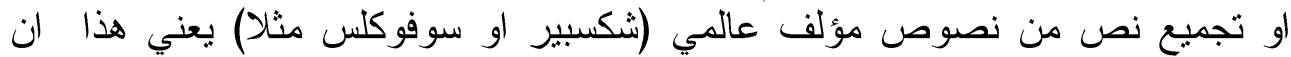

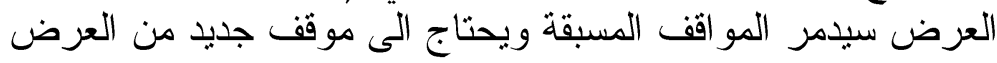

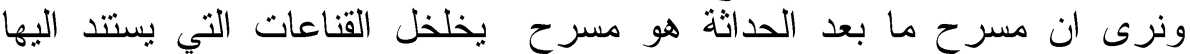
المتلقي، و يقوض قو اعد الحداثة الجمالية و الفكرية كما انه يستحيل الأستقرار او الثبات

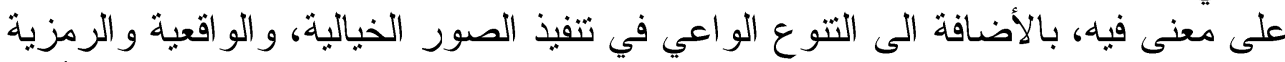

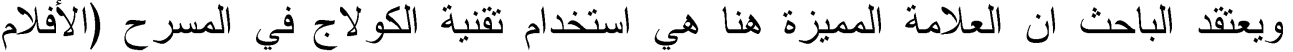

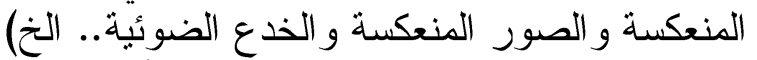

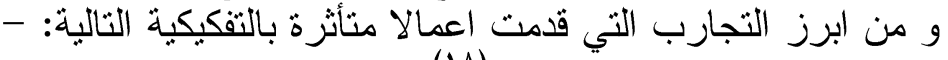

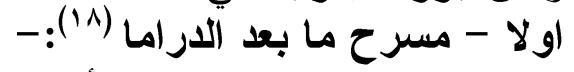

قدم لله الناقد والباحث الألماني هانز - تيز ليمان، استاذ المسرح في جامعة غوته فئه

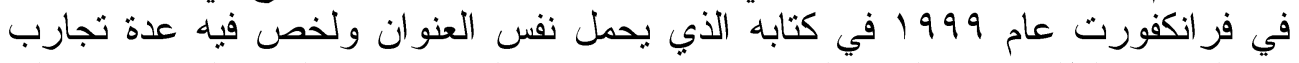

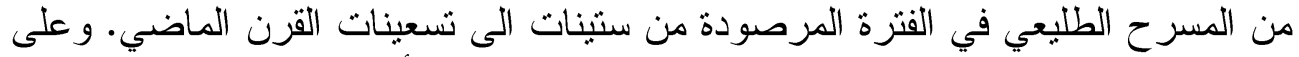

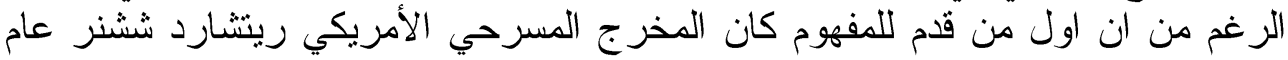

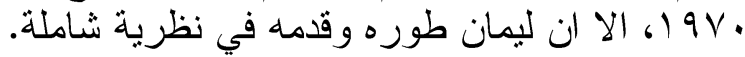

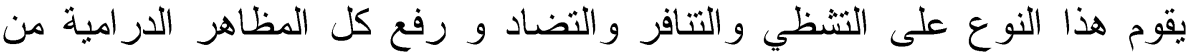

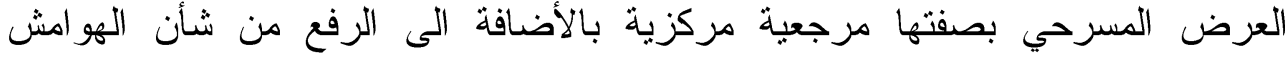

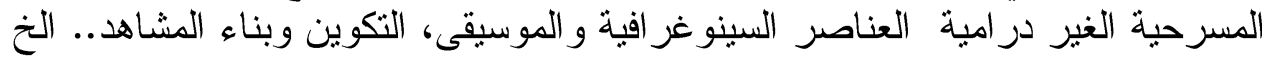

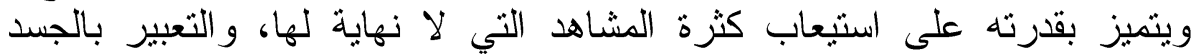

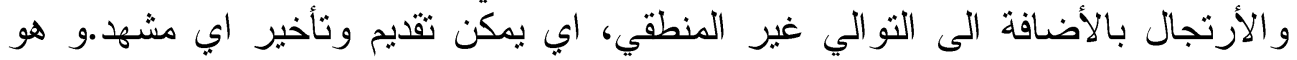

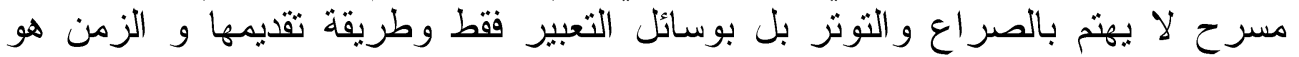

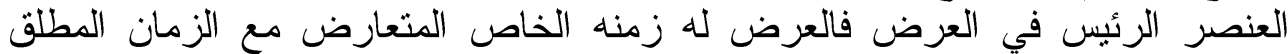

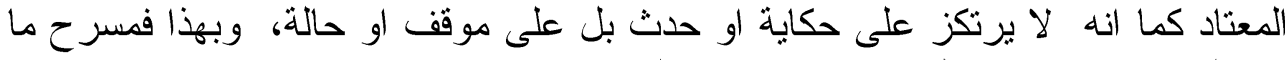

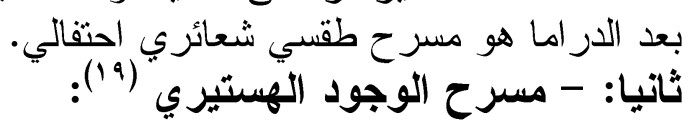

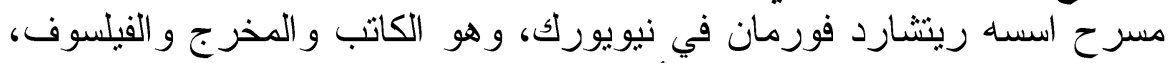

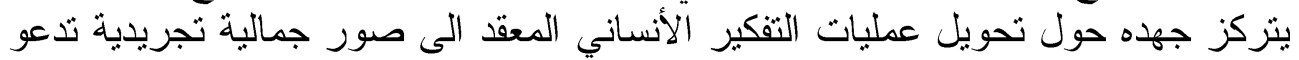

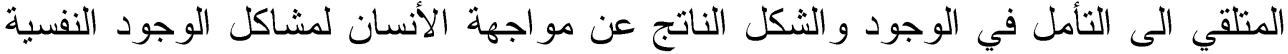

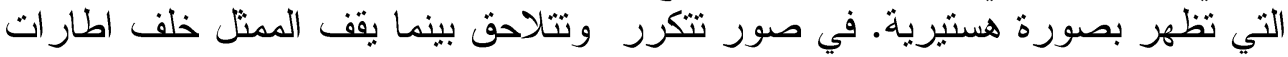

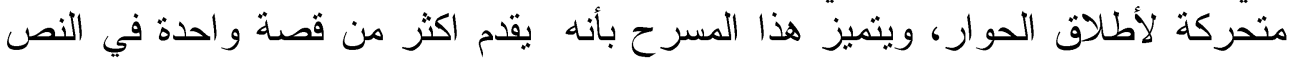

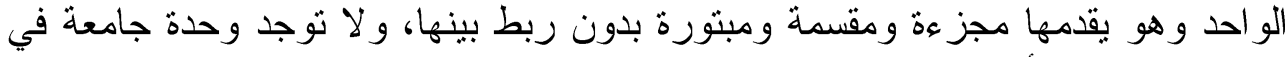

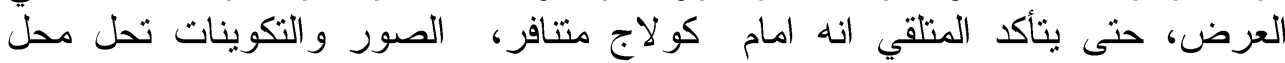

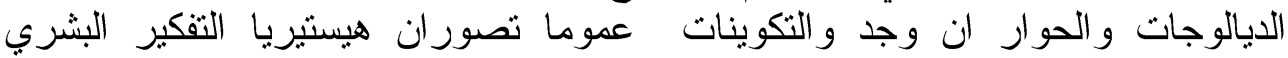
و التعقيد المستمر في الوجود المحيط بالأنسان كما يحاول فورمان الموازنة بين ما هو 
منطقي (السبب و النتيجة) و عشو ائي (التجز عة و التزكيب) وطارئ (الأرتجال) لأبقاء العقل

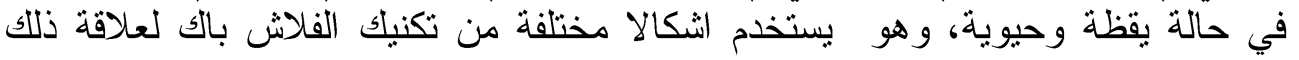

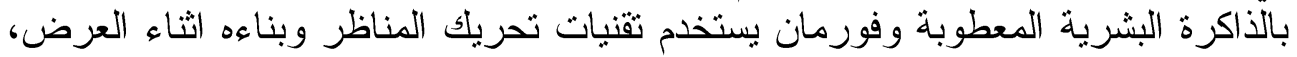

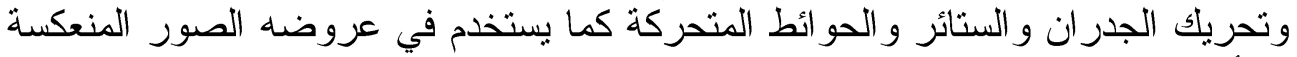

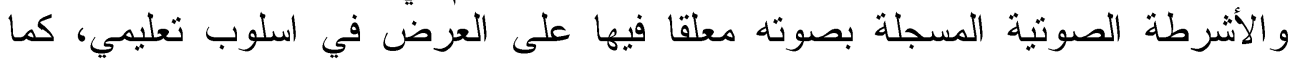

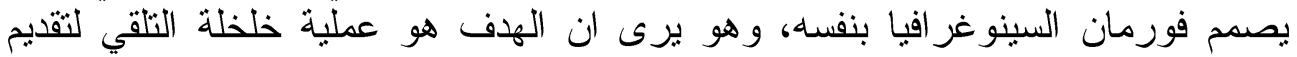

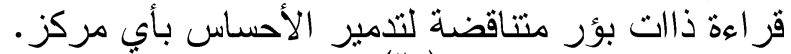

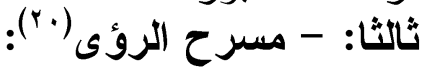

صاحب هذا المسرح هو روبرت هوبرت ويلسون وهو مخرج ومعماري ورسام، عانى في

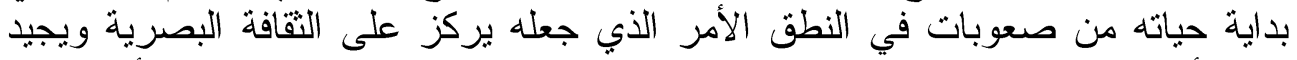

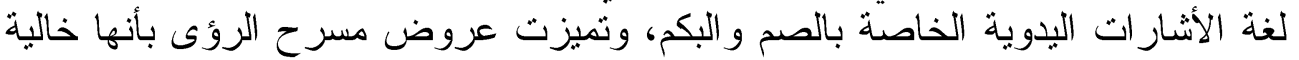

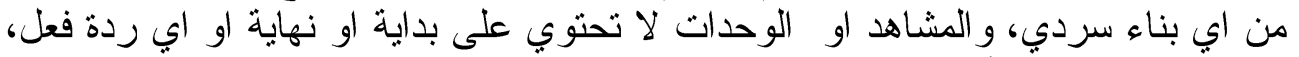

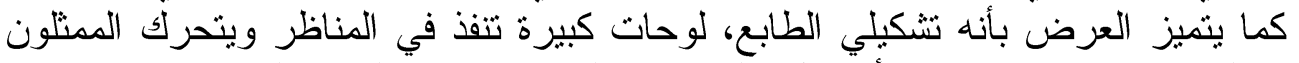

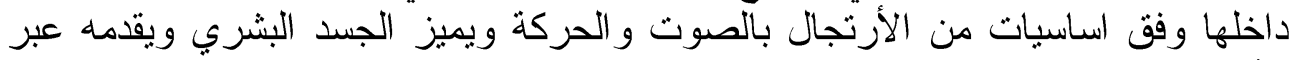

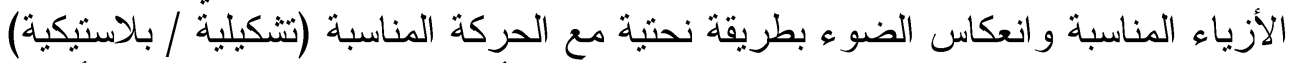

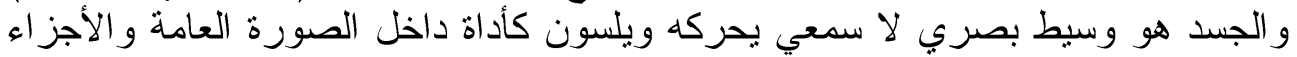

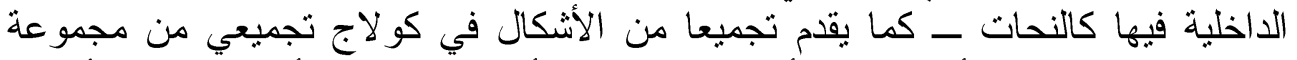

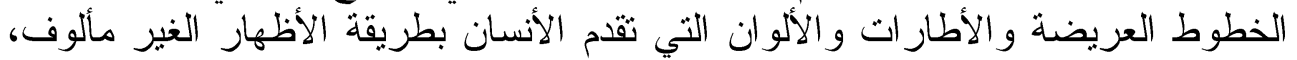

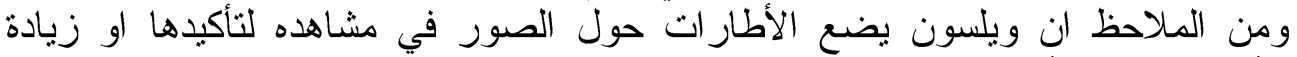

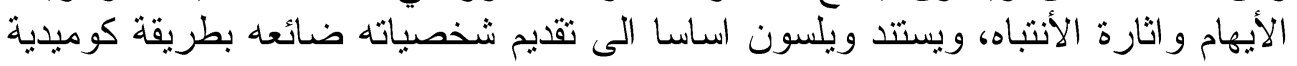

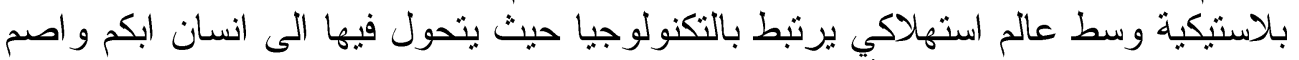

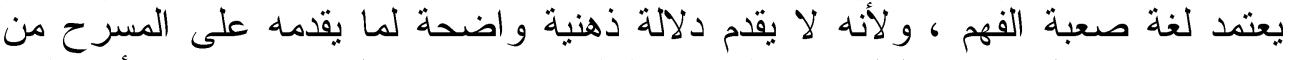

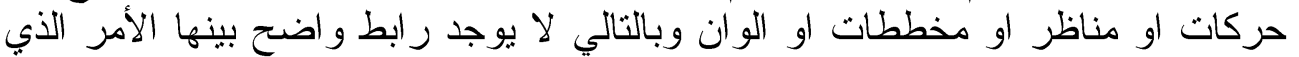

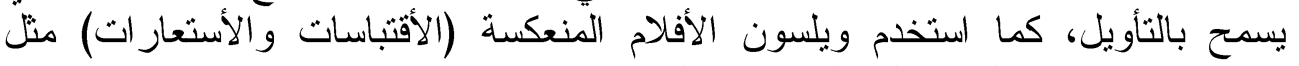

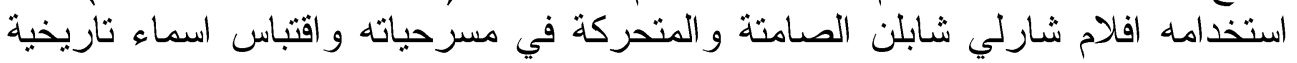
و اشخاص مشاهير لمسرحياته بموجب اسلوب الثاب تعسفي دون اي اعتبار للحقائق.

مناقشة الار استات السابقة

قام الباحث بالبحث على مواقع مكتبات البحوث على شبكة الأنترنت الدولية بسبب

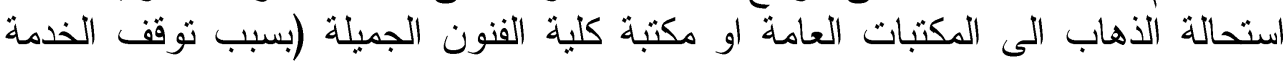

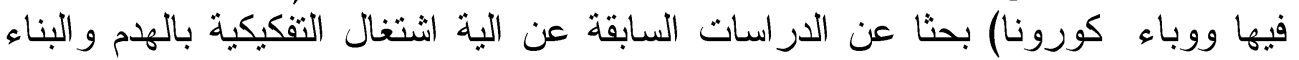

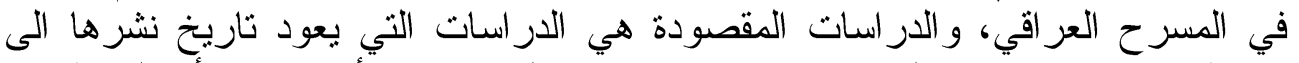

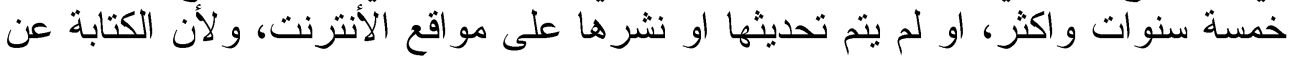

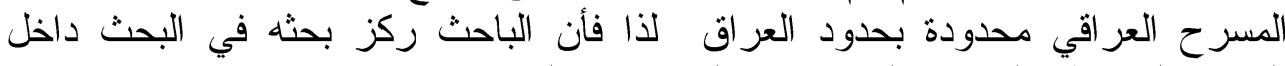

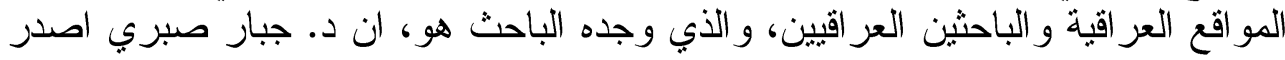

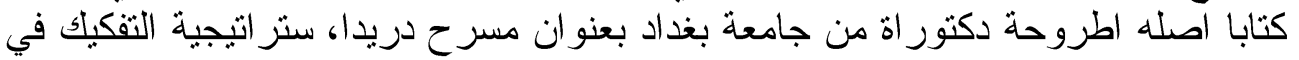

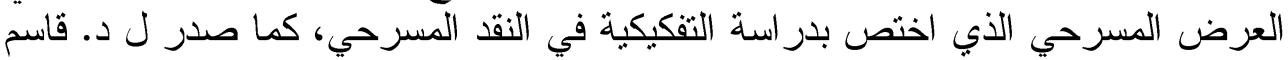

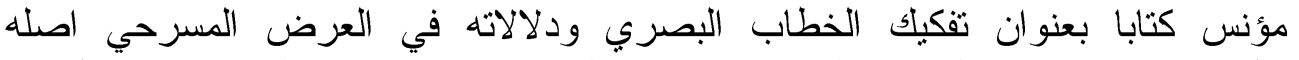

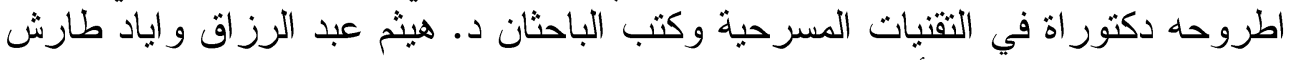

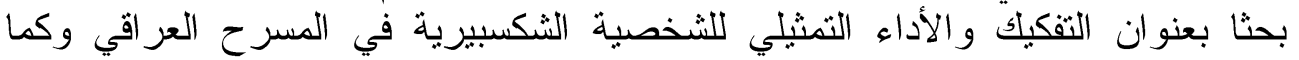
يوضح العنوان اختصاص البحث بدر استه للتفكيك في التمثيل، كما كتب احمد سلمان التهن 
عطبة بحثا بعنوان الحضور وتقكيكية جاك دريدا واشتخالاتها في المنظر المسرحي ونشره

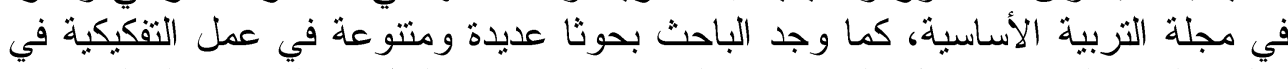

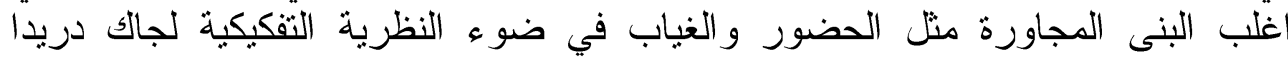

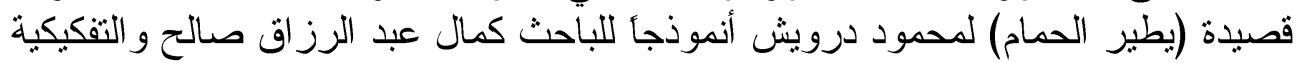

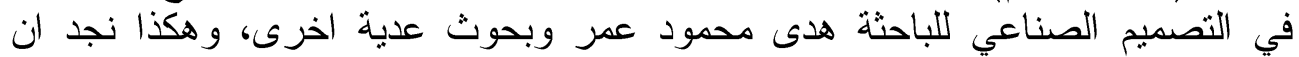

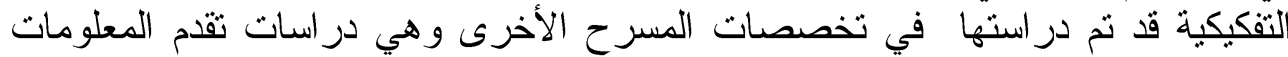

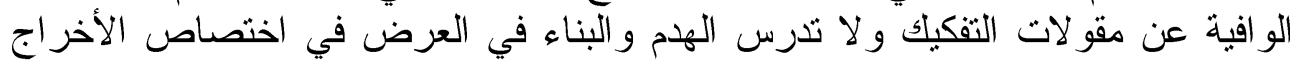

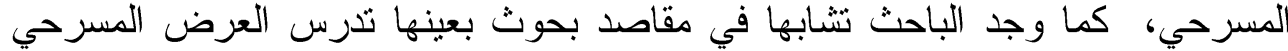

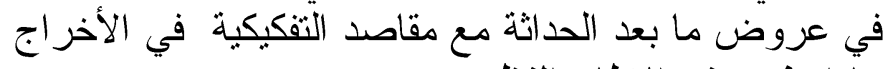

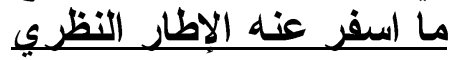

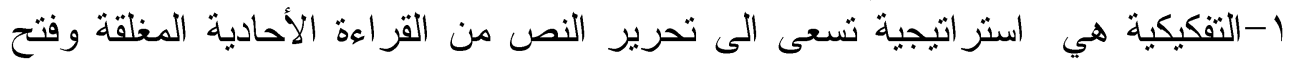

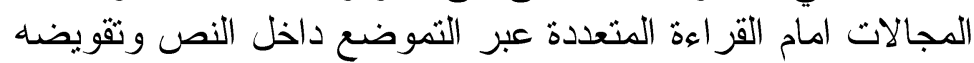

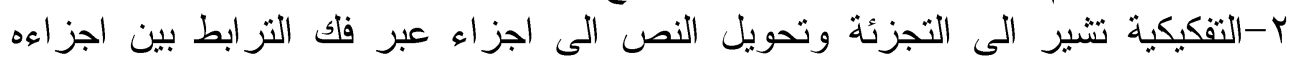

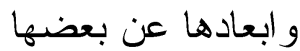

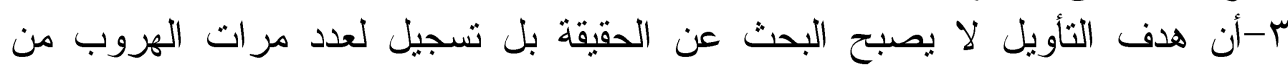

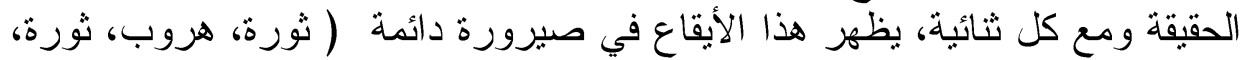

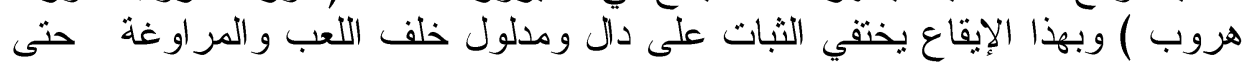

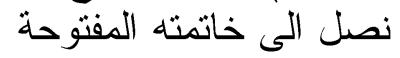

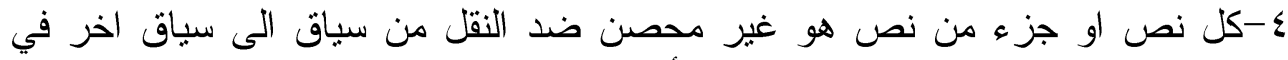

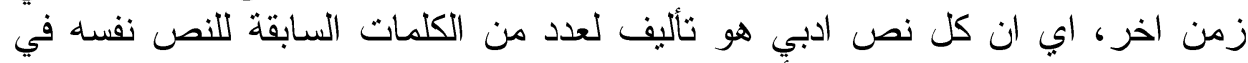

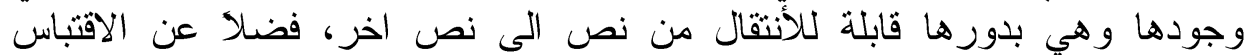

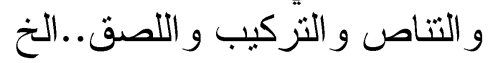
ه-بتأسس التأجيل عبر تحويل الزمان و المكان الى مفاتيح، عبر تأجيل الزمن والأنتقال بالمكان 7-التقكيكية اعتمدت الكتابة بدلا من الكلام لأن الكلام.. بعني احتكار سلطة الخطاب،

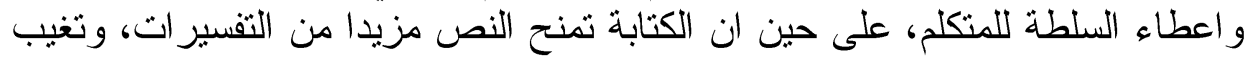

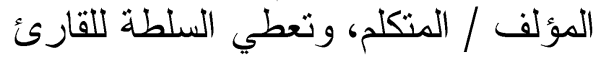

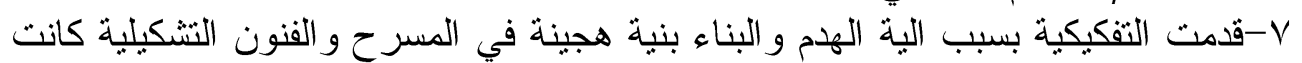

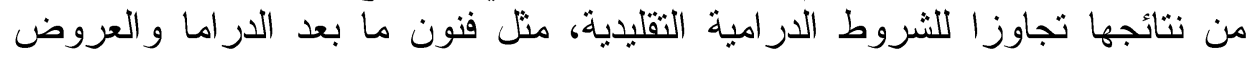

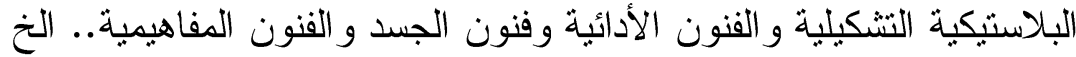

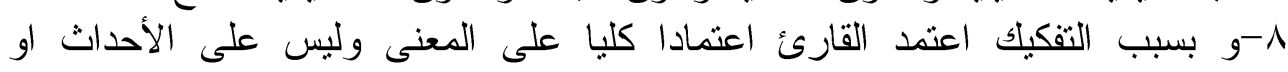

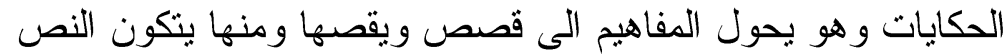

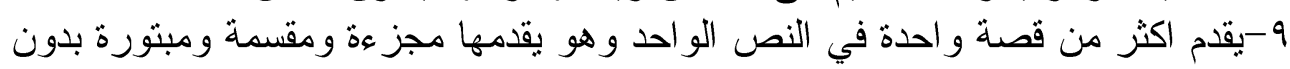

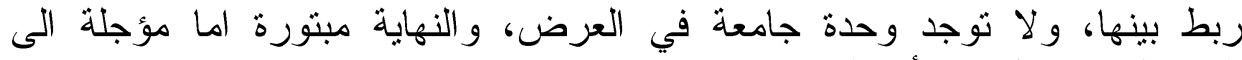
المستقبل او مقطو عة لأنها لن تحدث 


\section{الفصل الثالث}

أولاً: إجراعات البحث

1. مجتمع البحث البث

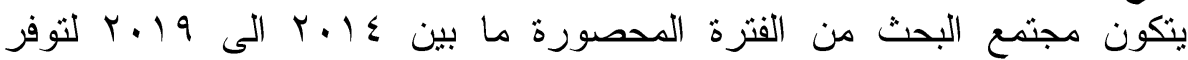

عروض تثناسب وعروض ما بعد الحداثة و المظاهر التفكيكية

r . عينة البحث

انتقى الباحث عبنة بحثه (عشوائبا ) وصو لا الى تحقيق الأهداف، كما مبين في

\begin{tabular}{|c|c|c|c|c|}
\hline تاريخ العرض & إخر اج & تأليف أو إعداد & اسم المسرحية & ت \\
\hline$r .17$ & جبار جودي & جبار جودي & خيانة & 1 \\
\hline$r \cdot 1 \varepsilon$ & انس عبد الصمد & انس عبد الصمد & توبيخ & $r$ \\
\hline
\end{tabular}

تم تصميم اداة البحث باعتماد الباحث المقومات الأتية: المؤشرات التي اسفر عنها الإطار النظري.

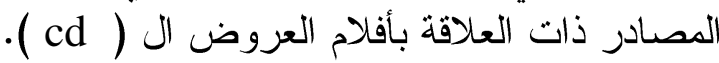

ع. منهج البحث

انتهج الباحث المنهج الوصفي (التحليلي) في البحث، كما ورد في أسلوب الإطار

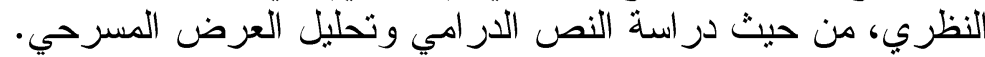

ثناتبا: - تعليل العينات: -

العينة الأولمى تصليل

مسرحبة خبينة

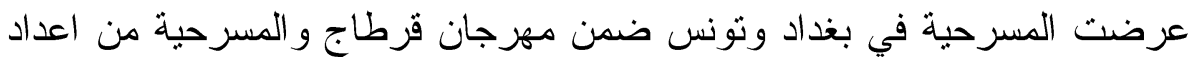

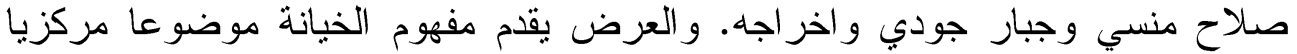

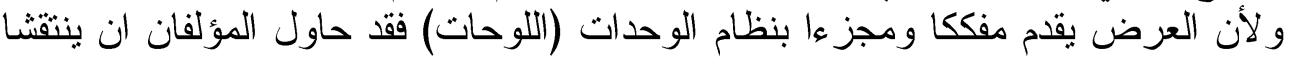

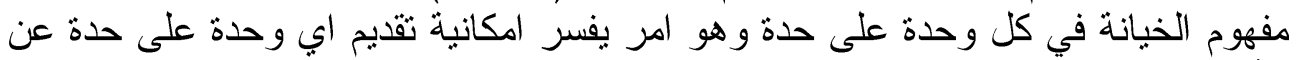
الأخرى دون ان يؤثر ذلك على العرض فالوحدات لا رابط بينها سوى مفهوم الخيانة

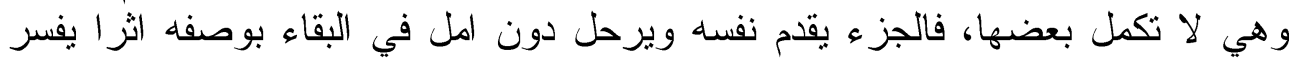

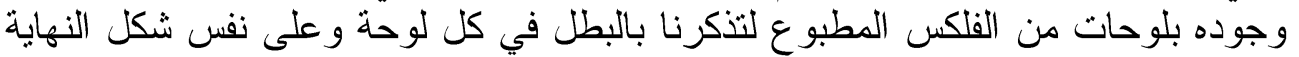

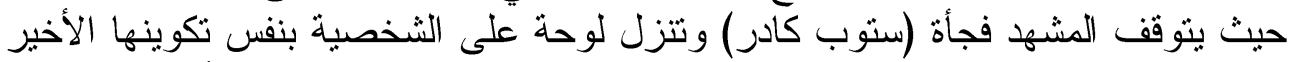

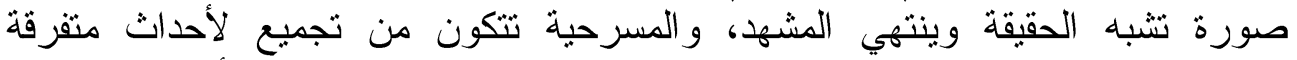

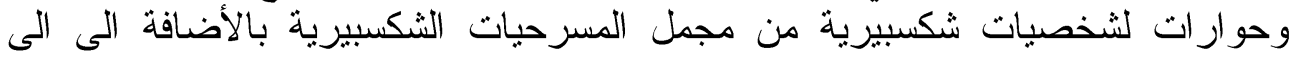
مفهوم الخيانة مع الشخصيات الثكسبيرية نفسها هذا من جهة. و ولأن المعدان على دراية الثية

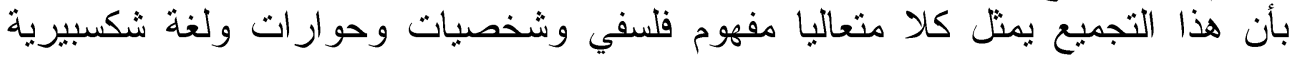

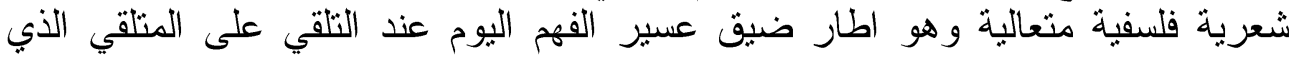
يحيا حياة عصرية سريعة قائمة على السرعة والأختصار لذارة لذا فقد قدم المعدان بالمقابل

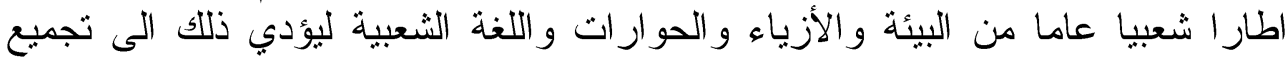

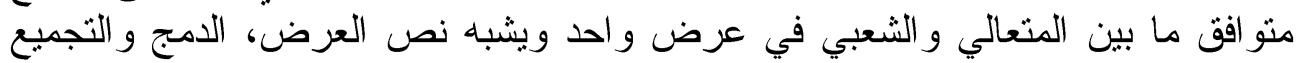

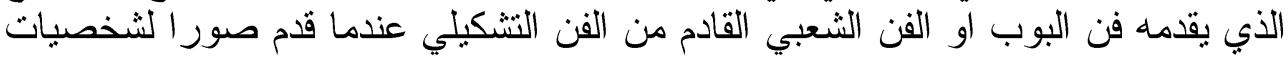


عالمية وكارتونية شهيرة في بيئة تجارية و اعلانية ويومبة ويعني هذا تحويل المتعالي ليكون في منتاول الجميع بنقله الى بيئة شعبية.

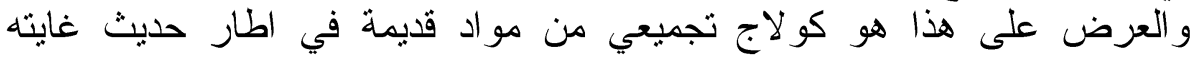

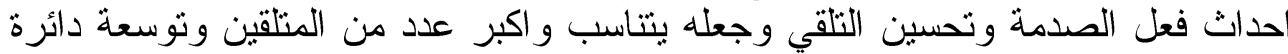

التأويل وتعدد القر اءات بحثا عن تعدد المعنى، وتمثل هذه العملية التجميعية تحو لات نو نوبن

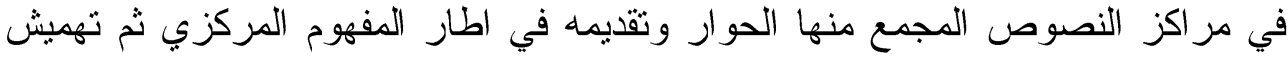

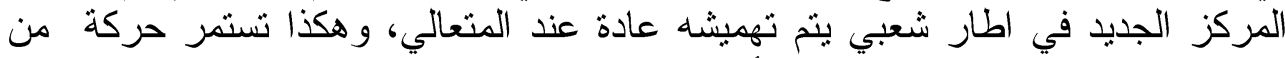

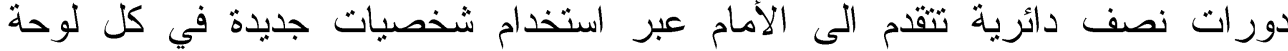
بوصفها بيادق يتم تقديمها والغاؤها حسب الموقف في كل وحدة مسرحية حتى نهاية

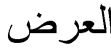

وناحظ الشخصيات عطيل الذي بختار موتا جديدا لدزدمونة بتتاسب والظروف المعاصرة بأن يتحول الى ارهابي يفجر القنابل و العبوات فيقرر قتلها بهذه الطريقة، بينما

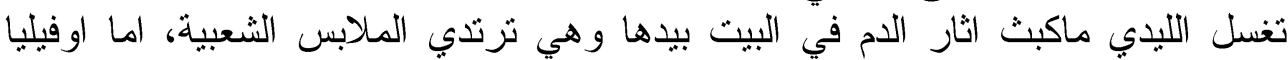

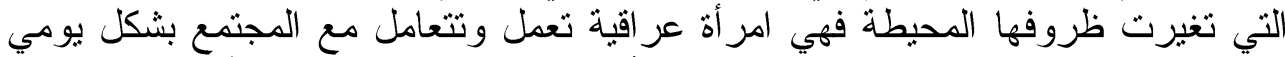

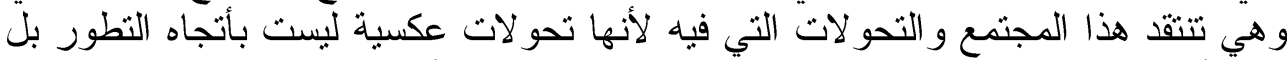

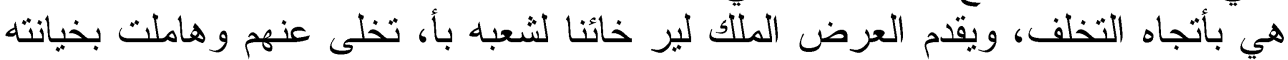

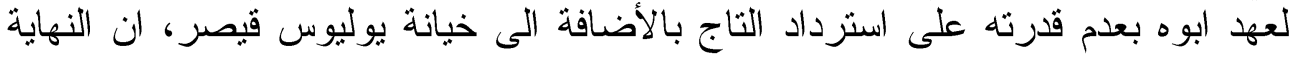

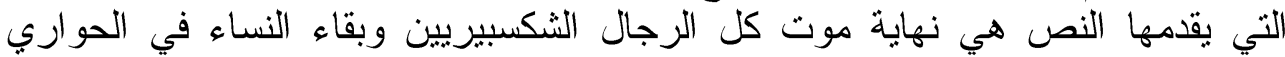

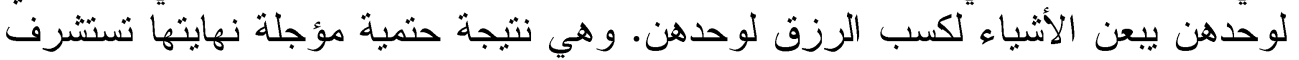

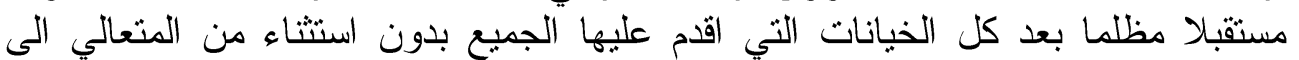
الشعبي

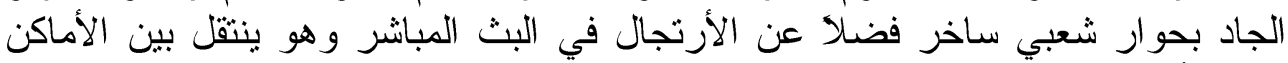

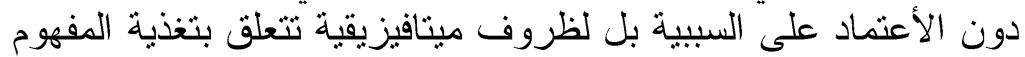

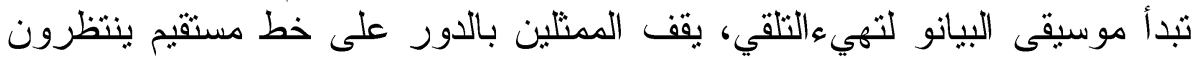
الدور ليتحدثوا عبر المايكروفون ويقدمون انفسهم، الشخصيات هي شخصيات شكسبيرية

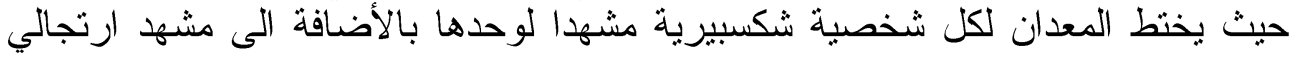

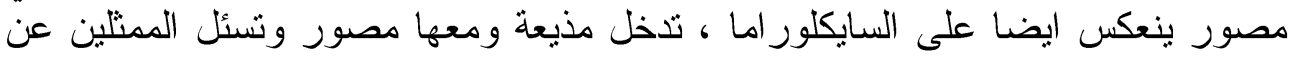

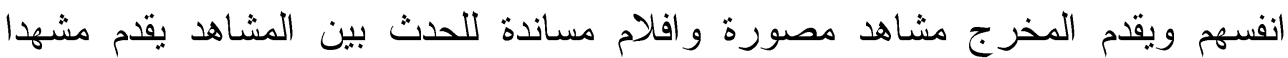

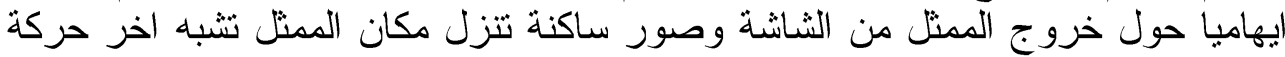
للممثل نفسه يليها اظلام وتتكرر هذه العملية مع كل مشهر وشخصية. و واستخدم ال stop) cader)

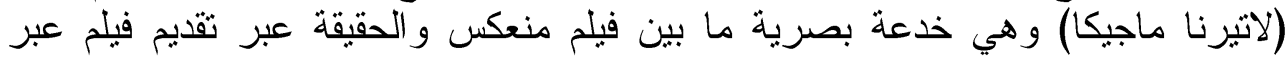

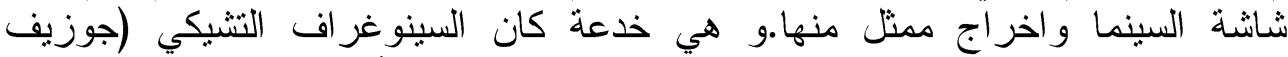

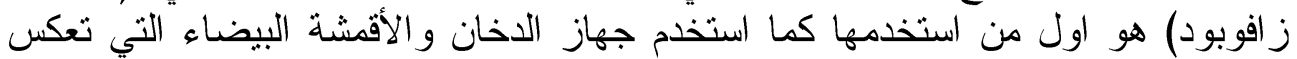

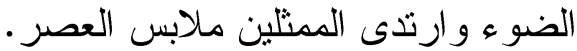

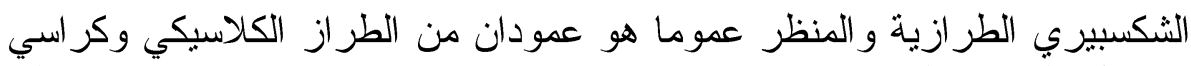

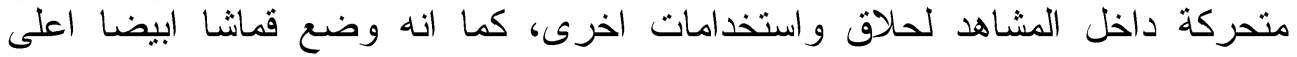


العمودين و الخشبة كما مزج العرض بين الموسيقى العالمية و اغاني عراقية مثل اغنية سعدي الحلي (غفة رسمك بعيني). و ينتهي العرض على اصوات ممزوجة مع صوت مذيع يقر أ بيانا من فترة الحرب

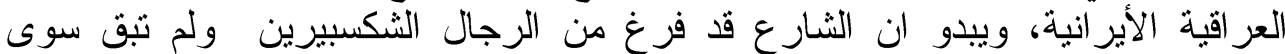

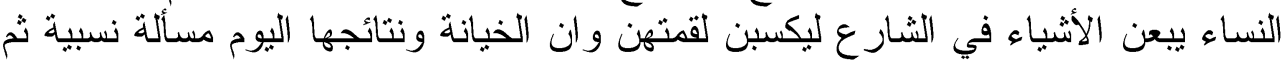
تطفيء الأضاءة على التّو الي التياء

إلعينة الثانية مسرحية توبنة مينة مينة

المسرحية من تأليف و اخر اج وتمثيل انس عبد الصمد، عرضت في بغداد وبنزرت

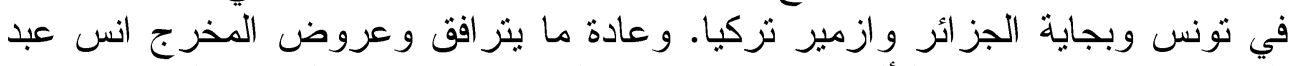

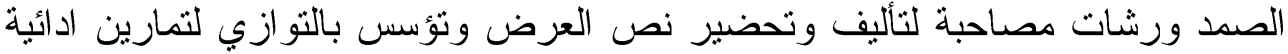
ومسرحية معتادة لتأسيس نص احس العرض.

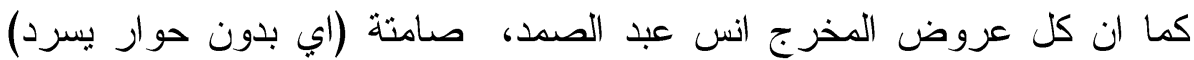
ويشمل ذلك مسرحية توبيخ، و التوبيخ هو مفهوم التهديد و الثانيب، ابتدأ الأمر من سؤ النيال

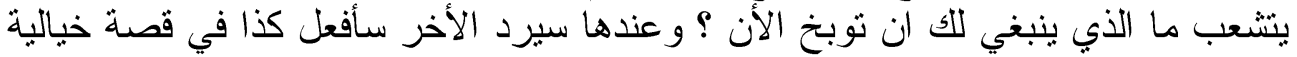

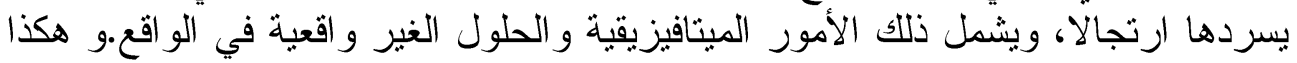

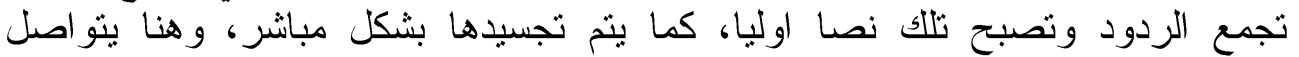

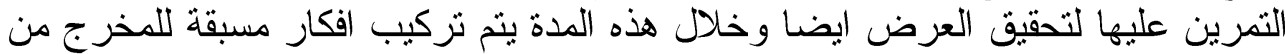

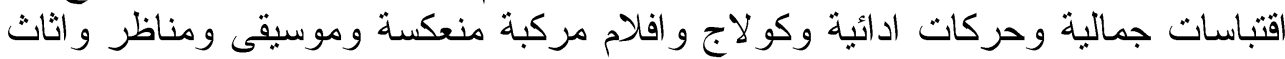

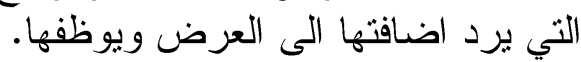

ان كتابة النص اثناء التجربة ومن المشاركين في العرض توفر فرصة توظيف

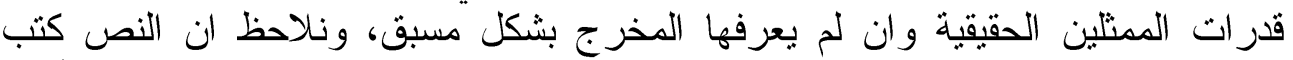

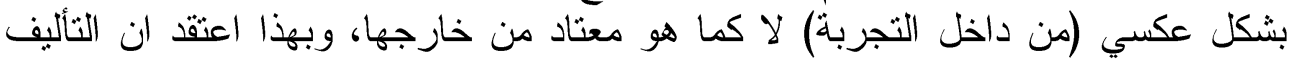
يجب ان يكون جماعيا لا من تأليف المخرج نفسه، وان كان هو من طور ونظم افكار

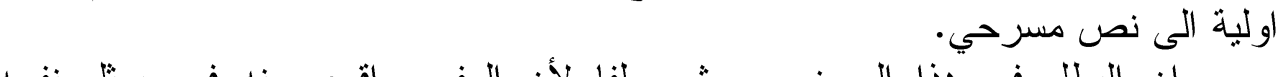
ان البطل في هذا العرض مهمش سلفا لأن المفهوم اقوى منه فهو يمثل نفسه

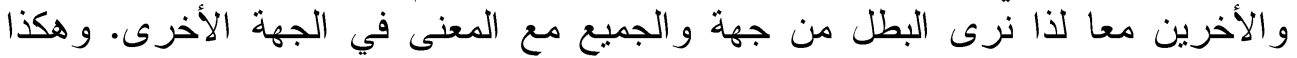

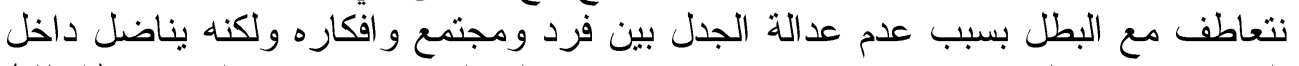

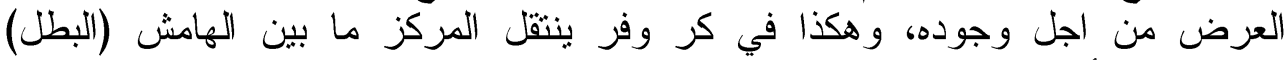

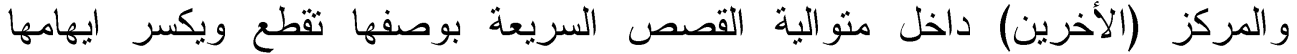

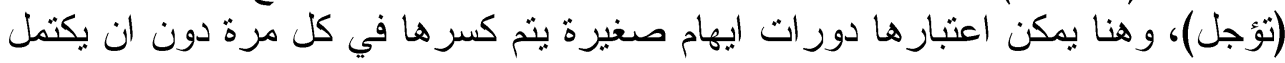

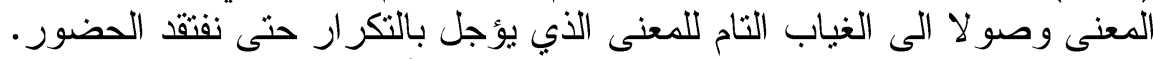

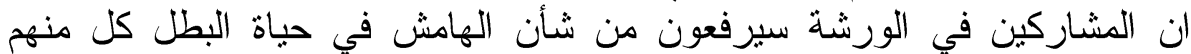

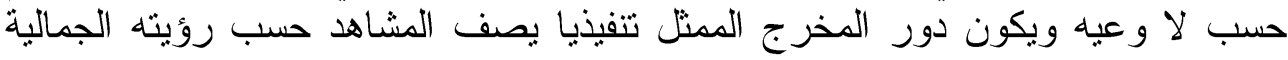

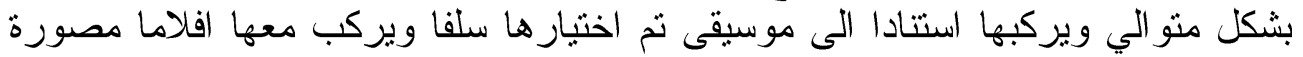

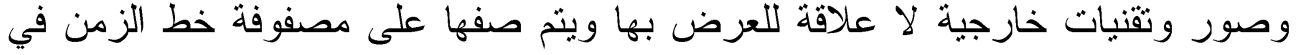

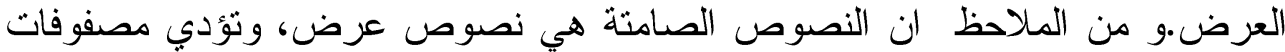

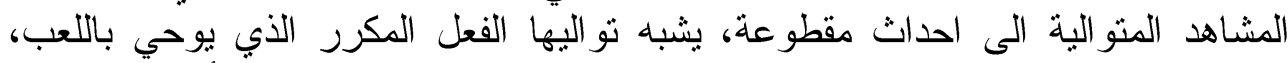
و هذه البنيات المتعددة تشبه المسرح داخل مسرح و المسرح ح الملحمي غير الأرسطي. 


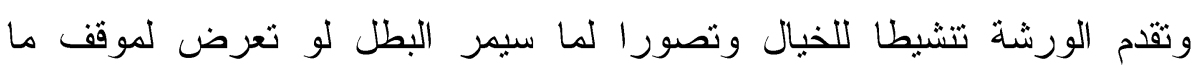

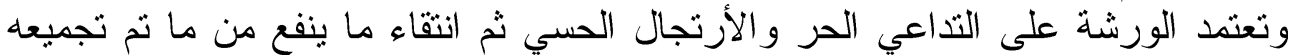

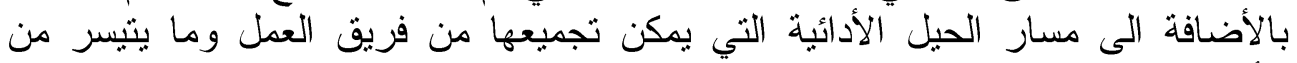

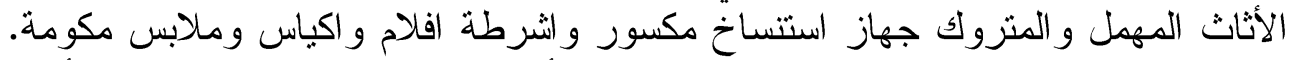
و ارتدى الممثلون الملابس الرسمية و البطل الزي الأبيض الكامل و المجموعة والزئلة الزي الأسود

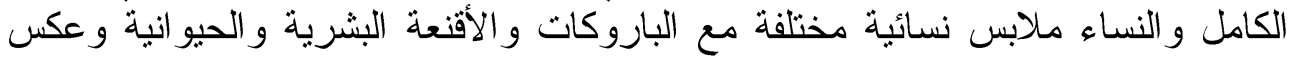

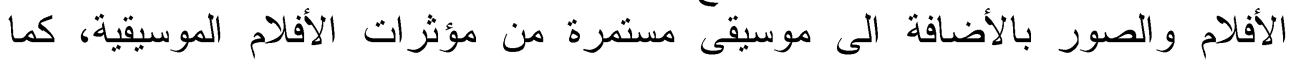

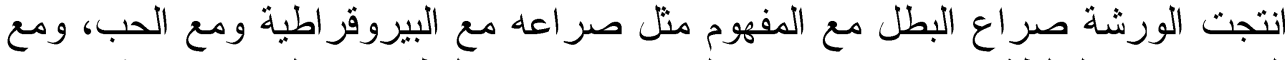

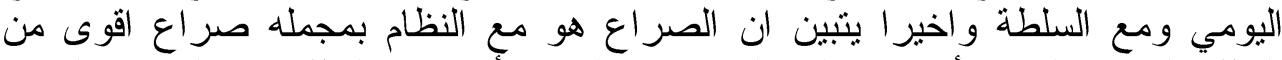

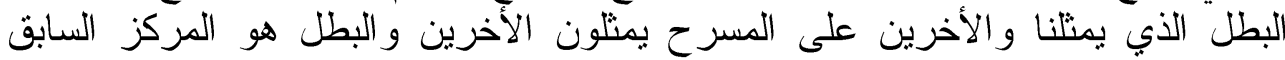

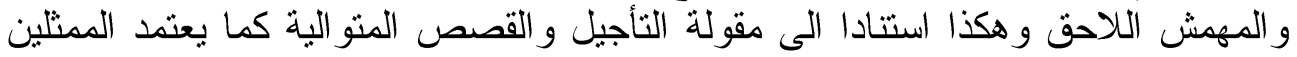
على ما اتفقوا عليه في الورشة بالأضافة الى منطقة من الأرتجال المسموح به الثيه اثناء

\section{الفصل الر ابع}

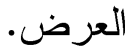

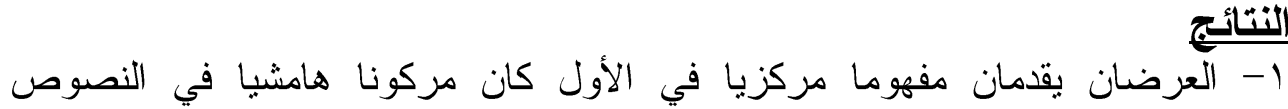

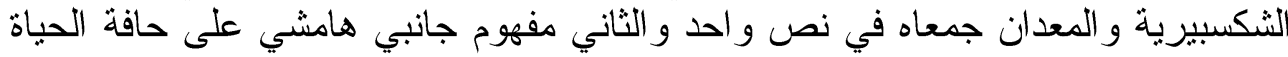
قدمه المخرج عرضا كاملان r- العرضان قدما نصوصهما مجزئين بنظام الوحدات r- الوحدات و الأجز اء لا تكمل بعضها، هناك امكانية لتقديم الو احدة على الأخر دون ان

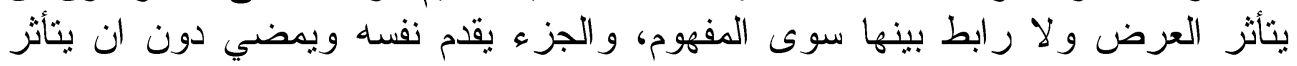
المعنى العام ع- في المسرحيتان مجموعة احداث متفرقة سبق تجميعها و اعيد ترتيبها وتركيبها، من

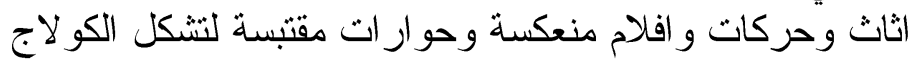
ه- الصر اع في العرضين بين المركز و الهامش التهات اللذان بيقيان في جدال لا نتيجة منه تذكر

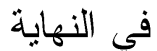
ج- العرضان يقدمان وحدات ايهام صغيرة مقطو عة ومبنورة بطريقة كسر الأيهام وبشكل

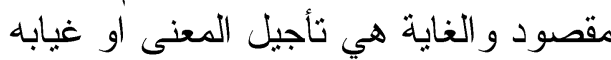
V- المسرحيتان لا تلتزمان بالقو التية اعد الأرسطية التقليدية و لا بالقو اعد اللا ارسطية التي

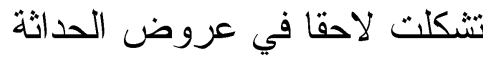

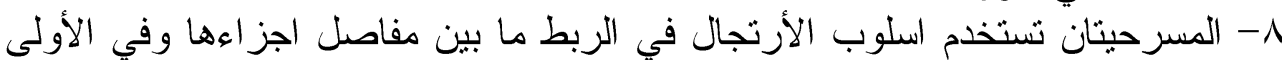

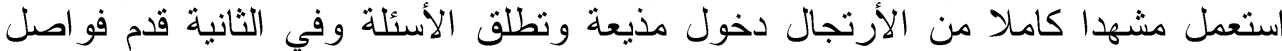

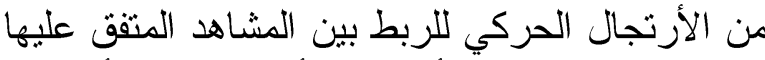

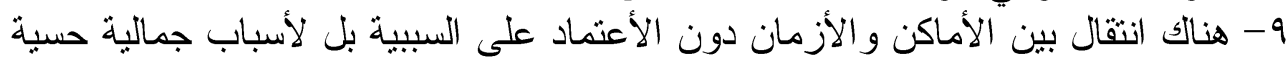
فقط

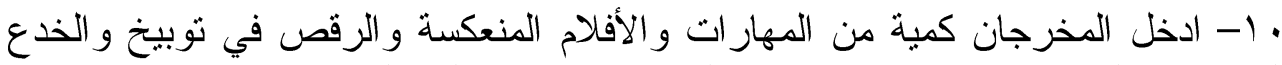

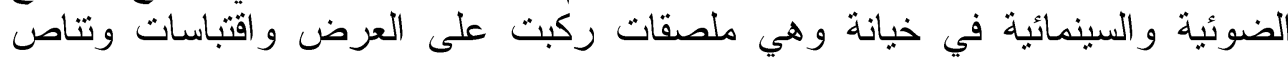
مقصود 


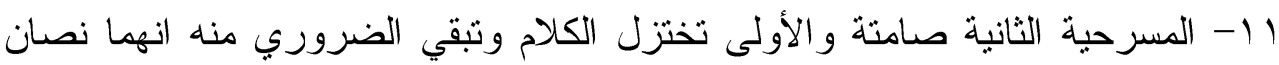
وصفيان بهنمان بالكتابة على حساب الكية والكام r أ- المعنى غائب بسبب التأجيل وقطع المعنى وكسر الأيهام و لا يوجد حضور بذكر في العرضين، كما ان النهاية مبتورة ومفتوحة فيهما | الأستنتاجات

1- العرض المسرحي التقكيكي هو الأساس في التحول التاريخي و الفكري لما بسمى بما

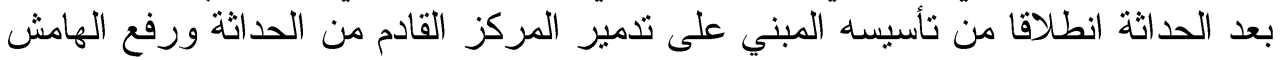

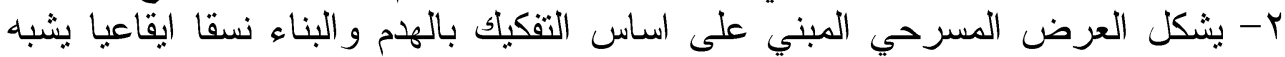
نصف الدائرة المنو اصلة و المترابطة على خط الزمن وهو في حالة دوران وتكرار

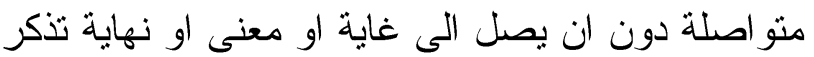

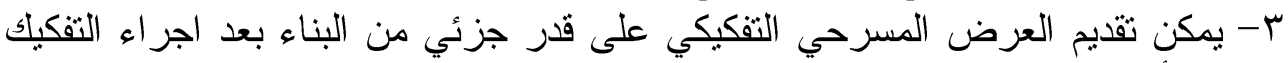

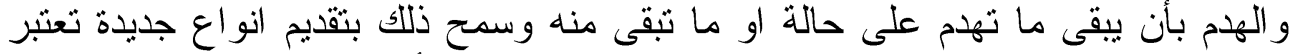

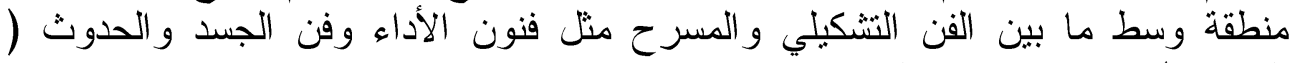

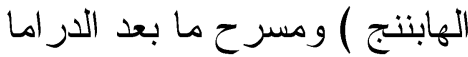

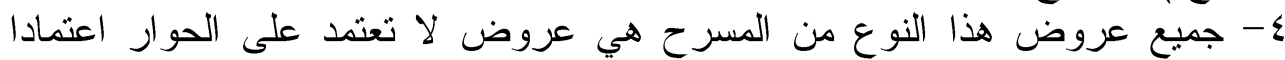

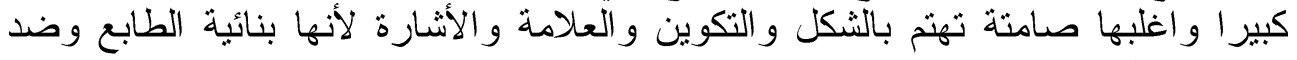
بنائية في الوقت ذاته التوصبيات 1- القامة مؤتمر علمي مسرحي للأحاطة بمقو لات و اساسيات هذا النوع من العروض

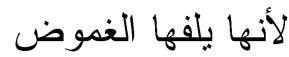
r- توفير المطبو عات و الكتب لغرض التعريف اكثر بهذا النوع من الأستر اتيجية الفلسفية النقدية من قبل المؤسسات المعنية ب- ان يؤسس لأجر اء بحوث علمية تبحث في التفكيكية بوصفها اساس لما بعد الحداثة المقترحات أبت 1- ب در اسة مقو لات التفكيك r- در اسة المسرح العر أقي بعد ب . . ب لكثرة هذا النوع من العروض 
" يادكار لطيف الشهرزوري، الظاهراتية و النقد الأدبي الأصول الفكرية للمناهج النقدية، دار الزمان

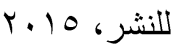

كا'- ميشيل فوكو : نظام الخطاب، ترجمة: محمد سبيلا، دار التتوير للطباعة و النشر و النوزيع، بيروت -

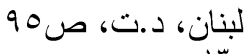
"بان- ميجان الرويلي، سعد البازعي، دليل الناقد الأدبي، المركز الثقافي العربي، الدار البيضاء، الطبعة

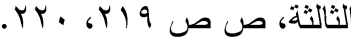

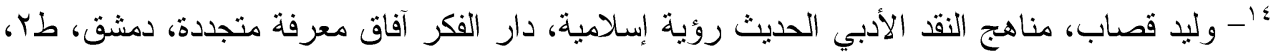
19V:صن. . . 9 10- البناء الفكري و الدرامي في نصوص الكاتب فؤاد التكرلي المسرحية، قو ائم رسائل واطاريح كلية

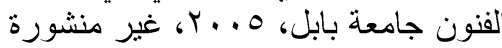

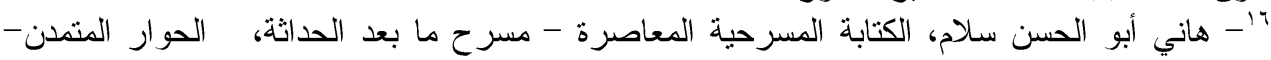

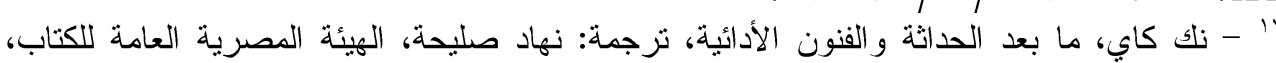
الألف كتاب الثانية، الطبعة الثانية،

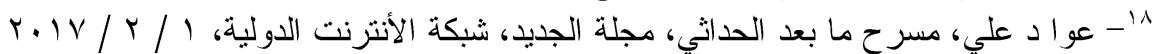

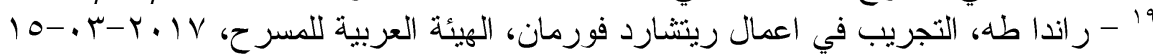

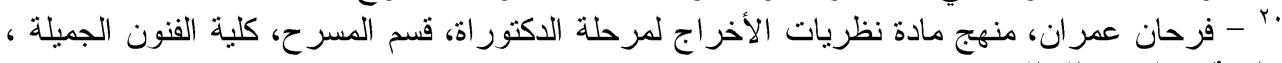

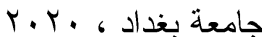

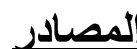

ا. ابو الحسين احمد بن فارس بن زكريا ، معجم مقاييس اللغة، تحقيق: عبد السلام هارون، دار الفكر،

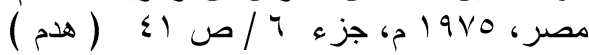

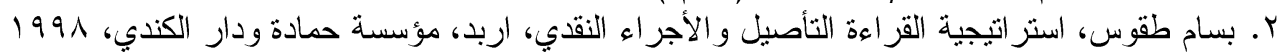

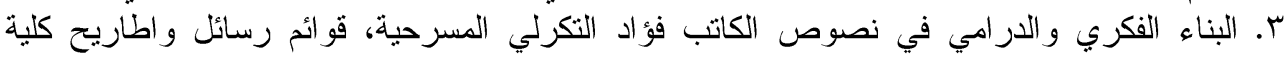

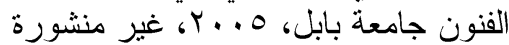

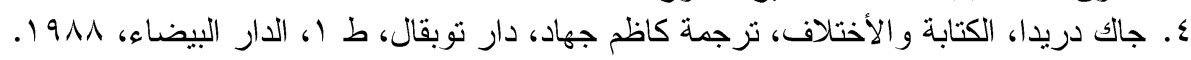

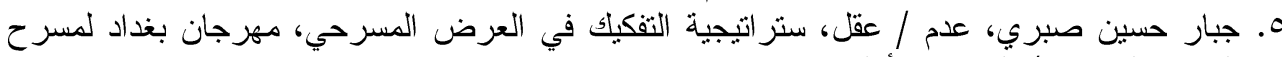

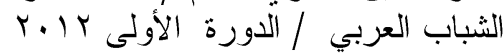

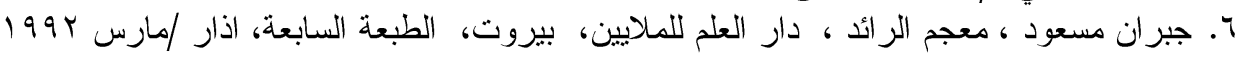

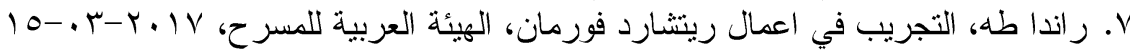

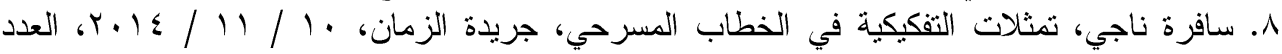
$V \leqslant 1$ 9. عبد الله إبراهيم وآخرون: معرفة الآخر مدخل إلى المناهج النقدية الحديثة، المركز التقافي العربي،

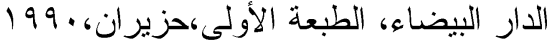
• • . عبد الله الغذامي، الخطيئة و التكفير من البنيوية الى التثريحية، دار سعاد الصباح، الطبعة الثالثة، 1994 1ا. عمر التاور، استراتيجية التفكيك عند جاك دريدا الهام والبناء، مجلة تبين، للاراسات الفكرية

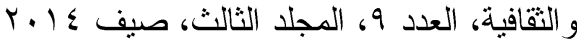

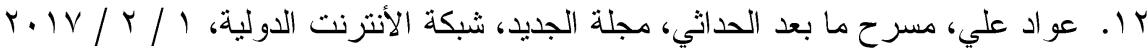

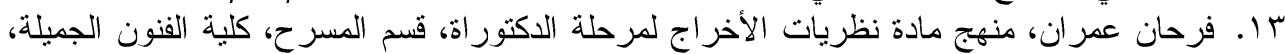

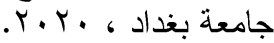

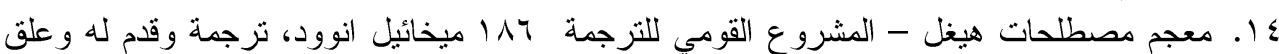

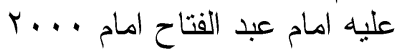
ه ا. ميجان الرويلي، سعد البازعي، دليل الناقد الأدبي، المركز الثقافي العربي، الدار البيضاء، الطبعة 
17. ميشيل فوكو : نظام الخطاب، ترجمة: محمد سبيلا، دار التتوير للطباعة و النشر و التوزيع، بيروت لبنان، د.ت

V ا. نك كاي، ما بعد الحداثة و الفنون الأدائية، نزجمة: نهاد صليحة، الهيئة المصرية العامة للكتاب، الألف كُناب الثانية، الطبعة الثانية،

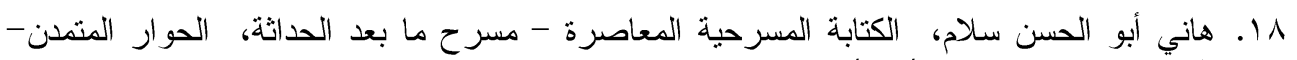

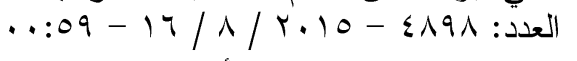

9 1. وليد قصاب، مناهج النقد الأدبي الحديث رؤية إسلامية، دار الفكر آفاق معرفة متجددة، دمشق، طب، .r. . 9

• r. يادكار لطيف الشهرزوري، الظاهراتية و النقد الأدبي الأصول الفكرية للمناهج النقدية، دار الزمان r. 